\title{
Financial Sector Surveillance and the IMF
}

Carlo Gola and Francesco Spadafora 


\title{
IMF Working Paper
}

Office of the Executive Director for Albania, Greece, Italy, Malta, Portugal, San Marino, and Timor Leste

Financial Sector Surveillance and the IMF

Prepared by Carlo Gola ${ }^{\circ}$ and Francesco Spadafora

\author{
Authorized for distribution by Arrigo Sadun
}

November 2009

\begin{abstract}
The global financial crisis has magnified the role of Financial Sector Surveillance (FSS) in the Fund's activities. This paper surveys the various steps and initiatives through which the Fund has increasingly deepened its involvement in FSS. Overall, this process can be characterized by a preliminary stage and two main phases. The preliminary stage dates back to the 1980s and early 1990s, and was mainly related to the Fund's research and technical assistance activities within the process of monetary and financial deregulation embraced by several member countries. The first "official" phase of the Fund's involvement in FSS started in the aftermath of the Mexican crisis, and relates to the international call to include financial sector issues among the core areas of Fund surveillance. The second phase focuses on the objectives of bringing the coverage of financial sector issues "up to par" with the coverage of other traditional core areas of surveillance, and of integrating financial analysis into the Fund's analytical macroeconomic framework. By urging the Fund to give greater attention to its member countries' financial systems, the international community's response to the global crisis may mark the beginning of a new phase of FSS.
\end{abstract}

\section{This Working Paper should not be reported as representing the views of the IMF.}

The views expressed in this Working Paper are those of the author(s) and do not necessarily represent those of the IMF or IMF policy. Working Papers describe research in progress by the author(s) and are published to elicit comments and to further debate.

JEL Classification Numbers: F33

Keywords: IMF, surveillance, macro-financial linkages

Author's E-Mail Address: fspadafora@imf.org

\footnotetext{
Carlo Gola, a former Senior Advisor to Executive Director at the IMF, is with the Bank of Italy. Francesco Spadafora is a Senior Advisor to Executive Director. The views expressed are the authors' only and do not involve the responsibility of the authors' employing institutions. For their useful comments, we would like to thank, without implying, Nicolas Blancher, Jim Boughton, Elie Canetti, Stijn Claessens, Peter Dattels, Gilda Fernandez, Nicola Giammarioli, Mangal Goswami, Daniel Hardy, Paul Hilbers, Ketil Hviding, Anna Ilyina, Kotaro Ishi, Ayhan Kose, Luc Laeven, Alfredo Leone, Isabelle Mateos y Lago, Christopher Morris, Jonathan Ostry, Luca Ricci, Arrigo Sadun, Carlo Sdralevich, Mark Swinburne, Ruud Vermeulen, Rene' Weber, Miranda Xafa, and Luisa Zanforlin. Daniel Mishel provided excellent editorial assistance.
} 
I. Introduction

II. Adding Financial Sector Issues to the Core Areas of Fund Surveillance ................................................ 8

A. Financial Sector Surveillance Before the 1994-95 Mexican Crisis ........................................ 8

B. Lessons from the Mexican Crisis: the February 1995 Biennial Review of Surveillance........12

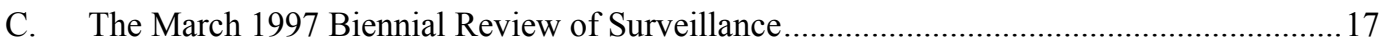

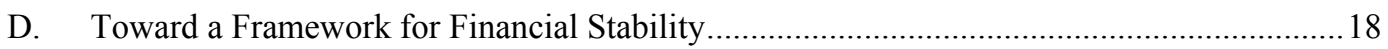

E. Lessons from the Asian Crisis: the March 1998 Review........................................................24

III. Financial Sector Surveillance in the Aftermath of the Asian Crisis ...................................................26

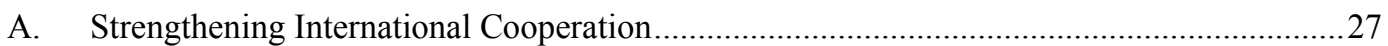

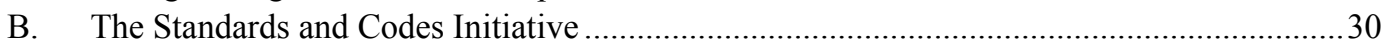

C. The June 1998 Guidance Note for the Monitoring of Financial Systems

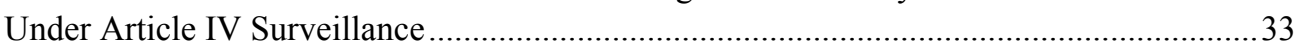

D. The Financial Sector Assessment Program ........................................................................ 34

E. The Development of Financial Soundness Indicators .........................................................40

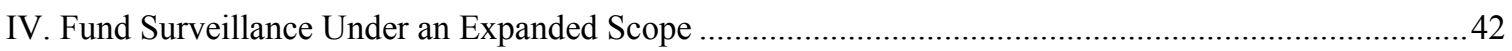

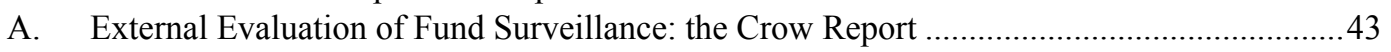

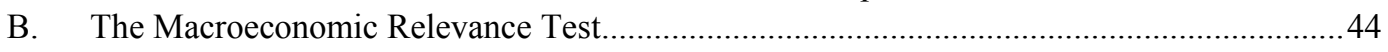

C. Bringing Coverage of Financial Sector Issues "Up to Par"

with Coverage of Other Core Areas of Surveillance ……....................................................46

V. Financial Sector Surveillance in the Aftermath of the Global Crisis.....................................................52

A. Integrating Financial Sector Issues into Macroeconomic Surveillance:

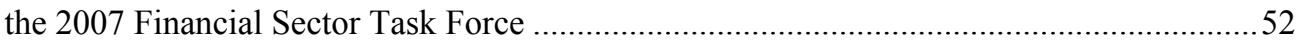

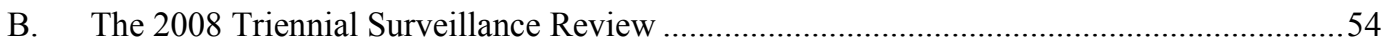

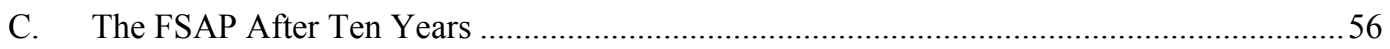

D. Integrating FSAP Assessments into Article IV Surveillance.................................................58

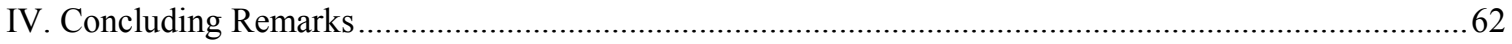

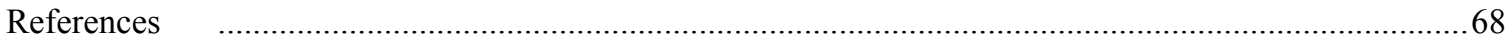

Boxes

1. Reforming the International Financial Architecture: Input from the International Community................14

2. Strengthening Surveillance Through Better Data Provision and Transparency:

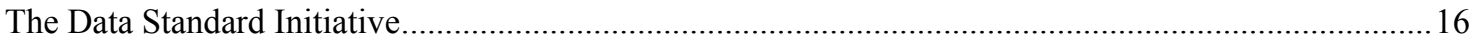

3. The Reasons to Build a Framework for Financial Stability .....................................................................22

4. Strengthening the Collaboration Between the IMF and the World Bank on Financial Sector Issues .......28

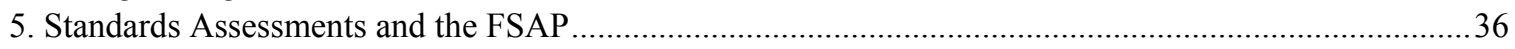




\section{INTRODUCTION}

The stability of the international monetary and financial system represents a global public good. In a sound macroeconomic environment, financial stability is a precondition for sustained economic growth. The global financial turmoil that broke out in August 2007 is the most vivid illustration of the fact that financial sector crises, by their very nature, can have disruptive effects on the real economy: they can trigger recessions, lead to large direct and indirect fiscal costs for the government, and entail major negative spillover effects at the international level.

Policies to avoid or lessen the likelihood and severity of financial crises are properly within the purview of the Fund's multilateral and bilateral surveillance. In fact, Article IV of the Fund's Articles of Agreement states, under Section 1 (ii), that the general obligations of members include seeking "to promote stability by fostering orderly underlying economic and financial conditions and a monetary system that does not tend to produce erratic disruptions." Moreover, under Section 3 (a), Article IV sets the requirement for the Fund to "oversee the international monetary system to ensure its effective operation...".

Article IV thus assigns to the Fund an institutional mandate to promote economic growth and financial stability, as well as to help prevent crises. Surveillance over member countries' policies remains the core activity of the institution's mandate, particularly through its focus on the linkages between the safety and soundness of the financial system and macroeconomic performance. Responsible policies at the level of national authorities, and proper practices by the private sector need necessarily to support the Fund's role in crisis prevention. Conditional lending and technical assistance complement surveillance in the Fund's toolkit for promoting financial sector stability and efficiency.

Although financial sector issues had been the object of the Fund's analysis for some time, the institution's systematic and intensive involvement in Financial Sector Surveillance (FSS) is relatively new. The Mexican and Asian financial crises of the mid-1990s marked a breakthrough in this regard. The role played by financial vulnerabilities in precipitating these crises and the significant economic costs suffered by the affected countries laid the groundwork for an unprecedented effort made by the international community toward the objective of strengthening the so-called "international financial architecture". In a context of growing economic and financial integration among all countries, sustained capital flows, and increasingly complex financial products, it became clear that macroeconomic and financial stability would crucially rely also on resilient and well-regulated financial systems.

Given its universal membership and relevant comparative advantages, the Fund took center stage, along with other international fora, in fulfilling the international mandate ${ }^{1}$ to develop

\footnotetext{
${ }^{1}$ The Fund's institutional mandate on surveillance is defined in the Articles of Agreement, and has not changed since April 1978, when the Second Amendment of the Articles came into effect (see Bougthon, 2001, Chapter 2). Unless specified, we sometimes use a broader and less formal definition of mandate, which intends to capture the expanded scope of Fund surveillance over time to cover financial sector issues. By "international mandate" we refer to the input and calls received from the international community, through the Fund's International Monetary and Financial Committee and such fora as the various " $G s$ " (G-7, G-20, G-24), which have directed the Fund to focus its attention and act on a range of issues that broadly fall within its institutional mandate. The latest examples of such input and calls are those included in the October 2008, April 2009, and
} 
both the analytical capacity and the operational tools to ensure the stability of financial systems across its membership.

The Mexican and Asian crises had indeed shed light on some weaknesses of the Fund's framework for surveillance, as financial sector issues had generally not received as much coverage as was the case for more traditional macroeconomic issues. The Fund thus became increasingly aware that more and better focused attention had to be paid by surveillance to monitor a country's financial sector, so as to identify risks and vulnerabilities and, ultimately, prevent financial crises.

Accordingly, reinforcing the Fund's FSS constituted one of the major components of the approach undertaken by the international community to strengthen the international financial architecture. The development and adoption of international standards and codes, and the enhancement in data provision and disclosure were two complementary elements of this approach.

For its part, the Fund embarked on a strategy aimed at making the institution the "center of excellence" for assessing the stability of the international financial system and preventing crises (IMF, 2000i). To this end, bilateral surveillance was directed to pay more emphasis on identifying external and financial sector vulnerabilities, as well as to systematically cover such vulnerabilities in staff reports. Additional guidance was provided to staff to assess a country's prudential regulation and supervision, and the linkages between the financial system and the macro economy. On the multilateral front, the establishment of the International Capital Markets Department in 2001 and the publication of the Global Financial Stability Report, starting from March 2002, were important steps in the effort to strengthen the surveillance of international financial markets.

Overall, the Fund's involvement in FSS can be characterized by a preliminary stage and two main phases. The preliminary stage dates back to the 1980s and early 1990s, and was mainly related to the Fund's research and technical assistance activities that accompanied the process of monetary and financial deregulation embraced by several member countries. Already at this stage, Fund staff underscored the importance of the so-called "macro-financial linkages", i.e., the two-way risk transmission channels between the financial sector and the real economy.

The first "official" phase of the Fund's involvement in FSS started in the aftermath of the Mexican crisis, and relates to the international mandate to include financial sector issues among the core areas of Fund surveillance. The second phase pertains to the efforts made to bring the coverage of financial sector issues "up to par" with the coverage of other "traditional" core areas of surveillance, as well as to integrate financial analysis in the Fund's traditional analytical macroeconomic framework.

October 2009 IMFC Communiqués, as well as in the G-20 Leaders Communiqués issued at the end of the Washington, London, and Pittsburgh Summits. For a broader discussion, see, for example, the Crow Report (IMF, 1999c, page 21-22): "So even though this mandate was originally intended to apply only to a strictly limited set of macroeconomic questions, when the international community thinks that surveillance is required in other areas - even if those areas go somewhat beyond the Fund's original mandate-the Fund is the obvious institution to call upon". 
As a result of the above process, the Fund has over the years significantly strengthened the financial analysis component of its multilateral and bilateral surveillance, including by progressively developing an analytical framework for financial sector assessments. The primary objective of this framework is to achieve an integrated analysis of issues related to both the stability and efficiency of the financial system, also relying on a wide range of analytical tools and techniques that have been progressively improved and expanded by Fund staff.

The Financial Sector Assessment Program is the Fund's flagship instrument for in-depth surveillance of a country's financial sector ${ }^{2}$. In its 2006 Review, the Fund's Independent Evaluation Office (IEO) judged the exercise "a distinct improvement in the IMF's ability to conduct financial sector surveillance and in understanding the important interlinkages between financial sector vulnerabilities and macroeconomic stability" ${ }^{3}$.

Perhaps the most uncontroversial outcome of the Fund's gradual involvement in FSS is that financial sector issues are now considered among the core areas of Fund surveillance. As underscored by the March 2000 Review of Surveillance (IMF, 2000a, p. 9):

"core issues have evolved from a narrow construction - exchange rate policies and their consistency with macroeconomic policies more generally - to cover financial sector, the capital account and cross-country influences".

More recently, the June 2007 Decision on Bilateral Surveillance over Members' Policies (IMF 2007b), in adopting the organizing principle of "external stability" to clarify the scope of surveillance and sharpen its focus, confirmed that financial sector policies are the subject of the Fund's bilateral surveillance, as they can significantly influence a country's external stability.

Against this background, the Fund's coverage of financial sector issues is not without controversies: for example, some complain about risks of "mission creep" important role played by the Fund in dealing with such issues is recognized even by those critics of the institution who advocate a narrowing of its mandate.

Notwithstanding the impressive effort put out by the Fund to strengthen the analysis of its member countries' financial systems and monitor global financial stability, the institution is now addressing the fallout from the global crisis that has originated in the most sophisticated financial markets in the world. The crisis spread to the real economy through an adverse feedback loop that was difficult to circuit break, and caused dire consequences all over the world.

The crisis has inevitably rekindled the question of why Fund surveillance (but hardly alone) was not fully effective in issuing strong and focused early warnings on the impending turmoil, so as to prompt correcting actions by country authorities.

\footnotetext{
${ }^{2}$ FSAPs are legally a form of technical assistance.

${ }^{3}$ IEO (2006, p. 1). See also the last review of the FSAP (IMF, 2009f).

${ }^{4}$ Truman (2006, p. 33-36).
} 
While many vulnerabilities and risks that subsequently developed into the global financial crisis had been identified, the Fund acknowledges that surveillance had underestimated the combined build up of systemic risks across sectors, as well as the quantitative impact of the feedbacks from the financial sector to the real economy, and their cross-country consequences (IMF, 2008c and 2009a).

Despite the long-standing emphasis on the analysis of macro-financial linkages, the Fund itself recognizes that surveillance missed the aggregate implications of individual risks, as macro-financial issues were often viewed in isolation, and spillovers and feedbacks inadequately explored (IMF, 2009a).

In this context, along with other international organizations and many national regulators, the Fund is being criticized for not having fully appreciated some of the risks posed by the emergence of a "shadow banking system" and the "originate-to-distribute" model of credit.

The above outcomes owes to a significant extent to serious gaps in the information needed for the assessment of financial system stability ${ }^{5}$, which also undermined the role of market discipline.

To be sure, both bilateral surveillance, through Article IV and FSAP reports, and multilateral surveillance, through the World Economic Outlook and the Global Financial Stability Report, had shed light on these developments and flagged several risks, but their warnings and remedial advice often lacked specificity (IMF, 2009a, p. 2 and 5) and, ultimately, were ineffective (or went unheeded).

Intense discussions are underway within the Fund to understand "what went wrong" and devise corrective measures. The 2008 Triennial Surveillance Review (IMF, 2008c), which took place in the midst of the crisis, has included two themes, which had been at the center of Fund surveillance for quite a while, among the areas deserving the highest priority in the period ahead: a more rigorous analysis and identification of macro-financial linkages (and related risks and adverse scenarios); and a fuller integration of financial sector surveillance into macroeconomic analysis, notably by ensuring that bilateral surveillance follows up in Article IV reports on the issues revealed in the FSAP exercise.

As demonstrated in the past by the Mexican and Asian crises, situations of global financial instability have historically been catalysts or accelerators of institutional changes, including for the international financial architecture and the role of the Fund and its surveillance activities. The current episode is no exception in this regard ${ }^{6}$.

At the Summit on Financial Markets and the World Economy, held in Washington in November 2008, the Heads of State or Government of the Group of Twenty laid the basis for a coordinated approach to address the global turmoil and enhance the resilience of the international financial system.

\footnotetext{
${ }^{5}$ IMF (2009b) outlines some of the key information gaps. They fall into two broad categories: 1) information that was either unavailable or not publicly disclosed; 2) gaps in information content. The latter gap is important, since "the use of the information to prepare effective early warnings was blunted in part because of attention on indicators that had limited or misleading information content" (p. 4).

6 "Strengthening IMF surveillance is probably the most complex issue growing out of the global financial crisis". Truman (2009, p. 7).
} 
The Summit Declaration, subsequently reinforced by the actions taken at the London and Pittsburgh Summits in April and October 2009 respectively, is most likely to represent the beginning of a new phase of FSS.

In particular, the London Declaration stated that the Fund, given its universal membership and core macro-financial expertise, should take a leading role in drawing lessons from the current crisis, consistent with its mandate and in close coordination with the Financial Stability Board and other standard setters. As far as Fund surveillance is concerned, the Declaration first reaffirmed the role of surveillance as a core tool underpinning the renewed efforts to strengthen the global financial architecture, and asked the Fund to "conduct vigorous and even-handed surveillance reviews of all countries" (Group of Twenty, 2008).

Equally important, the Declaration called on the Fund to give "greater attention to...[its member countries']... financial sectors and better integrating the reviews with the joint IMF/World Bank financial sector assessment programs". In the same vein, in its April 2009 Communiqué, the Fund's International Monetary and Financial Committee explicitly underscored the importance of "embedding financial sector surveillance more effectively as an element of the Article IV consultation... [as well as of]... integrating its results into the broader macroeconomic surveillance" (IMF, 2009d).

All in all, by underscoring the importance of the linkages across markets, sectors, and national borders, the global crisis has pushed financial sector issues even more to the center of Fund surveillance. At the same time, recent events have once again shown that the issuance of warnings on a country's risks and vulnerabilities is a necessary but not sufficient condition for the effectiveness of Fund surveillance. To put it differently, the quality of the Fund's analysis and policy advice (the output of surveillance) is something to a large extent separated from the impact (or "traction") of the Fund's warnings and recommendations on the actual policy choices made by policymakers (the outcome of surveillance). The full endorsement of the Fund's analysis and a timely follow-up on its advice on the part of country authorities, particularly those systemically important, are essential to ensure the effectiveness of surveillance, and preserve its nature as a public good that fosters economic and financial stability at the global level.

Against the backdrop of a string of new initiatives to enhance the global financial system and the Fund's early warning capabilities, the primary objective of this paper is to provide a comprehensive survey of the Fund's involvement in the systematic surveillance over its members' financial systems. In order to put into a historical perspective the renewed efforts in this area, the paper aims at illustrating the various conceptual and operational steps taken by the Fund along the process of placing more and more attention on the analysis of financial systems, including their regulatory and supervisory frameworks. This process culminated in the introduction, in 1999, of the Financial Sector Assessment Program (FSAP) and the Report on the Observation of Standards and Codes (ROSC).

It is important to underscore that while the focus of the paper is on bilateral surveillance, the analysis of risks and vulnerabilities in the global economic and financial system is the purview of the Fund's multilateral surveillance, distilled in its flagship semi-annual publications, the World Economic Outlook and the Global Financial Stability Report. In this regard, it is imperative to emphasize that in a highly globalized world, bilateral and multilateral surveillance have to be increasingly integrated and conducted in synergy with 
each other: on the one hand, multilateral surveillance pays attention to potential spillover effects to the global economy arising from the weaknesses in the financial systems of systemically important countries highlighted by bilateral surveillance; on the other hand, risks and vulnerabilities to the global financial system identified by the Global Financial Stability Report help inform financial sector surveillance at the country level.

This multilateral perspective that bilateral surveillance is increasingly taking on is arguably one of the main developments in the Fund's FSS in recent years. It recognizes that, in many countries, the effectiveness of bilateral FSS is weakened if it fails to take into accounts the developments in global markets and the related risks of cross-border spillovers. The latter are indeed receiving additional attention by Fund surveillance as a result of the global crisis.

The rest of the paper is structured as follows. Section II surveys the process of progressive inclusion of financial sector issues among the core areas of Fund surveillance following the Mexican and Asian crises. Section III focuses on the effort by the Fund to improve its toolkit for FSS, in the context of the initiatives undertaken by the international community in the late 1990s to strengthen the international financial architecture. Section IV illustrates the efforts made to bring the coverage of financial sector issues "up to par" with the coverage of other "traditional" core areas of surveillance, with particular attention to the need for finding a balance between comprehensiveness and depth of such coverage. Section V points to the post-global crisis initiatives toward a more rigorous analysis of macro-financial linkages and

a better integration between the FSAP and Article IV consultations. Section VI presents some concluding remarks.

\section{Adding Financial Sector Issues to the Core Areas of Fund Surveillance}

In this section, we first provide a brief overview of the preliminary stage of the Fund's involvement in FSS before the Mexican and Asian crises. This phase was mainly related to the Fund's research and technical assistance activities within the process of monetary and financial deregulation embraced by several member countries. Subsequently, we take a closer look at the consequences prompted by these two major crises, which laid the ground, together with the input from the international financial community (Box 1), for the progressive inclusion of financial sectors issues among the core areas of Fund surveillance.

\section{A. Financial Sector Surveillance before the 1994-95 Mexican Crisis}

Ever since the end-1980s and early-1990s, Fund staff had given considerable attention to the analysis of its member countries' financial markets, with special emphasis on the banking sector. One of the cross-cutting themes of these studies was the early recognition of the importance of the so-called "macro-financial linkages", that is the two-way relationship between the conditions of the financial sector and macroeconomic stability. 
The analysis of these important linkages, which are relevant not only for financial stability but also for the evolution of business cycles and long-term economic growth ${ }^{7}$, would explicitly inform the Fund's policy recommendations on how to strengthen the banking system.

It is first important to note that the analysis of the financial sector was carried out by Fund staff mainly in the context of multilateral surveillance and research. As far as bilateral surveillance was concerned, the focus of the Fund's work was generally not so much on the financial sector per se, but rather on the implications of financial sector liberalization for macroeconomic policies. As a result, the analysis of the financial sector remained, in most cases, at a fairly general level, constituting only the background for the assessment of traditional macroeconomic policies; besides, it was not tailored to capture the cross-country dimension of the problems affecting a country's financial sector.

\section{International Capital Flows and Systemic Risks}

In the 1980s and early-1990s, the Fund's analysis of the stability of financial markets was mainly carried out in connection with the process of growing integration of international capital markets, as this development had increased the potential for systemic risks and for large spillover effects of domestic macroeconomic policies.

Following up on a call from the Interim Committee to "continue improving the analytical and empirical framework underlying multilateral surveillance", in July 1990 the Fund's Executive Board ${ }^{8}$ discussed a paper on the determinants and systemic consequences of international capital flows (IMF, 1990). It was argued that the process of deregulation, globalization, and innovation in financial markets could be characterized as a "two-edged sword": on the one side, these structural changes had increased the efficiency of financial markets; on the other side, these developments, apart from possibly reducing the effectiveness of monetary and fiscal policies, had "increased volatility in financial markets and introduced new and highly complex risks, some of a systemic nature, which made the pricing of financial instruments more difficult and that can contribute to abrupt changes in credit flows once previously unforeseen risks become evident" (IMF, 1990, p. 49).

In fact, several crises, occurring in the 1970s and 1980s, had shown that monetary and financial reforms can have potentially destabilizing consequences if they are not properly sequenced and, equally important, supported by an efficient regulatory framework and a sound market infrastructure. Furthermore, these crises demonstrated that the potential contribution of international capital flows to improve economic growth could be realized only upon meeting a precise set of conditions. In particular, these flows would yield an efficient reallocation of savings across countries "only if global capital markets generate prices which appropriately reflect the underlying risks associated with holding financial

\footnotetext{
${ }^{7}$ See, for example, Claessens et al. (2008) for a comprehensive empirical characterization of the linkages between key macroeconomic and financial variables around business and financial cycles. See also Bayoumi and Melander (2008) for an analysis of macro-financial linkages in the United States.

${ }^{8}$ Throughout the paper, when we refer to the Board we intend the Executive Board. See also footnote 16.
} 
claims" (IMF 1990, p. 49). This condition, in turn, pointed to the need to overcome problems of incomplete or asymmetric information so as to allow an appropriate pricing of risk in these markets.

In terms of the policy options to contain systemic risks in international financial markets, Fund staff emphasized the case for adopting official measures in order to not only improve the discipline and consistency of monetary and fiscal policies (through surveillance and policy coordination), but also to limit contagion effects. The new capital adequacy standard for international banks, which would come fully into effect at the end of 1992, was singled out as an important step in this regard.

\section{Sequencing of Financial Sector Liberalization}

Major economic and financial developments in important emerging market economies stimulated Fund staff to devote a great deal of research to the process of financial sector liberalization and its effects on financial stability ${ }^{9}$. The optimal sequencing of financial sector liberalization was at the core of the staff's analyses over the years from 1988 to 1997, with a view to investigating the long-debated question of whether or not financial sector reforms can help trigger or aggravate financial crises.

These analyses are particularly interesting as they offer a clear picture of the approach followed at that time by Fund staff in dealing with financial sector issues. The underlying theme was that specific financial sector reforms should be properly sequenced and coordinated in order to reap their full benefits, in terms of efficiency and growth, as well as to complement and support macroeconomic stability.

In particular, the examination of country experiences showed that there were close structural linkages among the various components of financial sector reforms, and that these linkages had implications for the appropriate sequencing of these reforms. In fact, country experiences showed that financial liberalization typically involved two types of shocks: a monetary shock, i.e. a period in which credit growth exceeded the growth of deposits, and a portfolio shock, in the form of a surge in capital inflows following the removal of capital controls.

An orderly and well-supported financial sector liberalization was thought of as instrumental in preventing these shocks from leading to banking crises such as those that had occurred, for example, in Argentina, Chile, and the Philippines, which were accompanied by a sharp contraction in GDP.

In this context, staff research showed that the potential connection between financial sector reforms and financial crises derived from such factors as an unstable macroeconomic environment, the development of unsound liability structures by non-financial firms, and weaknesses in the institutional framework of the banking system.

\footnotetext{
${ }^{9}$ For example, some working papers prepared in this period were subsequently collected in Johnston and Sundararajan (1999). These authors defined financial sector liberalization as "a set of operational reforms and policy measures designed to deregulate and transform the financial system and its structure with the view to achieving a liberalized market-oriented system within an appropriate regulatory framework" (page 2).
} 
Importantly, it was pointed out that excessive risk taking on the part of banks and nonfinancial firms would be more likely if the deregulation of interest rates and bank portfolios or the liberalization of entry into the banking sector were not accompanied by adequate prudential regulation and supervision. The empirical evidence clearly showed that the failure to strengthen banking supervision appeared to be a critical weakness in a number of financial sector reforms.

Therefore, a major conclusion of staff's analyses was that well-designed, prudential regulation and vigilant banking supervision would make financial crises less likely and less costly, other than reducing the vulnerability of a financial system to the vagaries of the macroeconomic environment.

\section{The Banking Sector}

Although staff's analysis was paying attention to the general aspects of global financial markets, a particular focus was placed on the banking sector and the consequences of a crisis taking place in this sector ${ }^{10}$.

Fund staff started looking systematically at some banking crises (Argentina, Chile, Malaysia, the Philippines, Spain, Thailand, and Uruguay) that occurred from the mid-1970s all through the 1980 s, with a view to better understanding the contributing factors ${ }^{11}$. The methodology followed a case-by-case approach, aimed at identifying the underlying causes in the evolution of a number of macroeconomic and financial variables. The analysis was largely retrospective, focusing on explaining the events rather than on predicting future occurrences.

It is important to note that such retrospective analysis of banking crises emphasized explicitly the linkages between macroeconomic conditions, financial sector reforms, and financial crises. In fact, despite the diversity of the cases, the two-way relationship between macroeconomic and financial conditions stood out as a crucial common feature of these episodes. A key lesson from these crises was that "although macroeconomic instability can weaken the portfolio of financial institutions, weaknesses in the financial sector can have feedback effects on the economy, and seriously complicated adjustment and growth policies" (Sundararajan - Baliño, 1991, p. 1).

Staff recognized that the real effects of a banking crisis occur not only indirectly through changes in interest rates and the money stock, but also more directly through the impact on credit markets, the balance of payments, and the economic activity. It was also underscored that real investment and growth would be depressed not only by a "credit crunch", but also by the large and pervasive uncertainty that is generated by a banking crisis.

\footnotetext{
${ }^{10}$ In particular, the Central Banking Department and, subsequently, the Banking Supervision and Regulation Division of the (expanded and renamed) Monetary and Exchange Affairs Department promoted several Selected Issues papers on banking crises with important policy implications.

${ }^{11}$ Sundararajan and Baliño (1991).
} 
This latter feature is all the more evident in the dynamics of the recent global crisis, where the freeze of interbank markets results from the uncertainty about the health of bank balance sheets and the distribution of "toxic" mortgage-related assets.

Moreover, staff's analysis explored in depth the relationship between banking crises and credit markets in order to understand the role of these markets in initiating or aggravating the crisis and the direction of causality (from credit markets to the real sector or vice versa). Supported by the empirical evidence from some countries, staff crucially emphasized the possibility that disturbances in credit markets unleashed by a banking crisis "served to depress output to levels below what might have been expected from the changes in relative prices and in real returns of investment" (Sundararajan - Baliño, 1991, p. 10).

Equally important, it was pointed out that the very conduct of monetary policy would be affected by a banking crisis, as this is usually associated with substantial portfolio shifts (e.g., increases in the demand for money) that have an impact on the money multiplier and the stability of the monetary base. Moreover, the very conduct of monetary policy could be affected by the measures taken toward crisis resolution: for example, the increase in central bank credit to assist ailing financial institutions might jeopardize the attainment of monetary and balance of payments targets. In the same vein, the design of monetary (and fiscal) policy could be complicated by an approach to crisis resolution that shifted the bulk of the banks' losses on the government or the central bank. All in all, these arguments showed that, in a financial crisis, central banks could face a difficult balancing act between the objective of preserving monetary stability and the fulfillment of their lender-of-last-resort obligations (Sundararajan - Baliño, 1991, p. 35).

As a result of the Fund's increasing attention on the soundness of its member countries' banking systems, the design of IMF-supported programs and technical assistance started to progressively place more focus on such issues as banking legislation, regulation, supervision, and the framework for crisis resolution ${ }^{12}$.

\section{B. Lessons from the Mexican Crisis: the February 1995 Biennial Review of Surveillance}

It was only with the 1994-95 Mexican crisis, and following the input from the international community, that the Fund began to draw more systematic attention to financial sector issues. The devaluation of the Mexican peso on December 20, 1994 set off what the former IMF Managing Director, Michel Camdessus labeled as "the first financial crisis of the twenty-first century". In fact, the crisis represented the first major event to hit an emerging market economy in the new globalized world.

While other crises had already displayed similar features (for instance Chile in 1982 or the Nordic banking crises in the early $1990 \mathrm{~s}^{13}$ ), it was the Mexican crisis that exposed

\footnotetext{
${ }^{12}$ See Enoch-Marston-Taylor (2002) for a collection of papers reflecting Fund staff's experiences in assisting member countries to resolve banking sector problems.

${ }^{13}$ See Drees and Pazarbaşioğlu (1998).
} 
dramatically the macroeconomic consequences of the increasing globalization of capital markets and the growth in cross-border capital flows.

The crisis marked the start of the efforts on the part of the international community toward strengthening the so-called "international financial architecture". In fact, over the following years, the Fund's involvement in FSS would result, to a significant degree, from the interactions between the inputs received from the international community, with a leading role played by the Group of Seven (G-7), and the advances made by the institution in analyzing and monitoring the stability of financial systems.

The Halifax Summit of the G-7 in June 1995 (Group of Seven, 1995) was a defining moment for the Fund, on account of the decision by the G-7 to expand the scope of surveillance so as to include financial sector issues among its core areas (Box 1).

Before Halifax, the evolving role of the Fund and the new challenges for surveillance in an environment of increased globalization of financial markets had already been discussed by the Executive Board in February 1995 on the occasion of the 1995 Biennial Review of Surveillance (IMF, 1995b).

The Board first endorsed a two-pronged approach to improve the availability of data for the purpose of surveillance (Box 2), since lack of transparency was deemed to be the single most critical factor in causing the Mexican crisis. Furthermore, to identify emerging difficulties in member countries at an early stage, specific operational measures were aimed at ensuring a more continuous and effective surveillance ${ }^{14}$.

The review made the Fund aware that the goal of improving the scope and focus of surveillance would require innovations along two dimensions: countries and issues. On the first one, the Fund would have to be more selective, by concentrating its attention on countries at risk, particularly those exposed to regional or market spillovers and swings in capital flows. Systematically important countries and those with large borrowing from the Fund would also have to receive particular consideration.

More importantly for the subject of this paper, one of the most consequential conclusions of the 1995 review was that Fund surveillance, while giving the highest priority to its core issues, was directed to pay more attention, in a selective way, to capital market and financial sector developments. In particular, staff was asked to allow greater coverage of financial sector issues in Article IV consultations for those members where market issues were especially relevant; it was also encouraged to make better and more regular use, in its internal analyses, of the wide range of financial market data available outside the Fund. Finally, there was a call for strengthening regional surveillance and for closer monitoring of economies where economic developments had the potential to spillover into other countries.

A further analysis of the relationship between the financial crisis and the conduct of Fund surveillance was carried out a few months after the Biennial Surveillance Review, when the

\footnotetext{
${ }^{14}$ Firstly, it was agreed to supplement annual Article IV consultations with interim staff visits and six-month reviews of members' policies, as well as to increase the use of "follow-up" procedures in selected cases. Secondly, the Board would hold more informal cross-country meetings through so-called "country matters sessions", with the aim of reviewing, on a regular basis, economic conditions and policies in all Fund members.
} 
Board discussed an internal confidential document, the Whittome Report ${ }^{15}$ (IMF, 1995c), named after its author, Sir Alan Whittome, a former Fund Director and Counselor. The objective of the report was to assess how the Fund had dealt with the evolving situation in Mexico, in the context of its surveillance, during the two years preceding the crisis.

While restating the detrimental role played by insufficient data provision, the Board was unanimous in considering that the Fund's relations with Mexico in the period leading up to the crisis illustrated some serious shortcomings in the way the institution had practiced its surveillance.

All in all, the discussions on the 1995 Biennial Surveillance Review and the Whittome Report made it clear that surveillance would have to be strengthened if the Fund were to successfully detect financial crises at an early stage. The conclusions from the above discussions were distilled in the April 1995 Executive Board's Report on Strengthening of Fund Surveillance (IMF, 1995d) transmitted to the Interim Committee, the Fund's primary advisory committee to the Board of Governors ${ }^{16}$.

Reaffirming that the globalization of capital markets and the growth in cross-border flows did carry the potential for a rapid transmission of disturbances across markets and economies, the Board agreed that while the objectives of surveillance would remain unchanged, "its practice... [needed]... to evolve so that the Fund can adequately meet new challenges" (IMF, 1995 d, p. 1). This would require a number of key ingredients, including improved procedures for surveillance and efforts to adapt the culture of the Fund to the challenging environment of increasingly globalized capital markets.

\section{Box 1 - Reforming the International Financial Architecture: Input from the International Community}

The Halifax Summit of the G-7 in June 1995 marked a crucial moment as to the contribution of the international community toward the objective of strengthening the international financial architecture, as well as for the role of the Fund in FSS.

The Summit represented the beginning of the "Architecture Exercise" (Kenen, 2001) and started a new phase of activism by the G-7 in the governance of global finance. In fact, this informal body acquired a leading role in setting the international financial policy agenda, identifying all the relevant elements of the international financial architecture and linking those elements in a consistent strategy ${ }^{17}$. Starting from Halifax, the challenges

\footnotetext{
${ }^{15}$ While the report has never been made public, the Board discussion on it is indeed available to the public and references to it are included in the 1995 IMF Annual Report.

${ }^{16}$ Within the Fund's structure of governance, the Board of Governors is the highest decision-making body. It consists of one governor and one alternate governor for each member country. The Board of Governors has delegated most of its powers to the 24-member Executive Board, which takes care of the day-to-day work of the IMF. This work is guided by the International Monetary and Financial Committee (formerly the Interim Committee), and supported by the IMF's professional staff. The Managing Director is the Head of IMF staff and Chairman of the Executive Board. He is assisted by a First Deputy Managing Director and two Deputy Managing Directors, and together they constitute the Fund's management.

${ }^{17}$ See Saccomanni (2000) for a thorough analysis of the international monetary reforms in the 1990s, culminating in the report of the G-7 finance ministers to the Köln Summit in June 1999. See also, Saccomanni (2008), in particular chapter 6 .
} 
posed by financial crises, the appropriate response to them and, more generally, the reform of the International Financial Institutions (IFIs) have become a "hardy perennial" of G-7 discussions (Sobel and Stedman, 2006).

The Halifax Summit was first notable for having directed the Fund to expand the scope of its surveillance so as to explicitly cover developments in member countries' financial and banking sectors. It also assigned the Fund the task of improving data provision and transparency (Box 2).

\section{Strengthening Prudential Regulation and Supervision}

Another remarkable development of the Halifax Summit was the recognition that closer international cooperation in the regulation and supervision of financial institutions and markets was essential to safeguarding the global financial system. Subsequently, the Lyon Summit of the G-7 Heads of State and Governments in June 1996 sanctioned the role of better prudential regulation and supervision of financial markets as the "principal crisis-preventing strategy of the Architecture Exercise" (Kenen, 2001, p. 91).

Noting that the globalization of financial markets had contributed to the creation of a more complex financial environment, the G-7 attached importance to "the implementation of improved practical measures to deal with risks relating to the operation of global financial markets" (Group of Seven, 1996). The G-7 hence called for the adoption of strong prudential standards in the banking systems of emerging market economies as "essential elements in preserving the stability of the international monetary and financial system" (Group of Seven, 1996), and encouraged the international financial institutions to increase their efforts to promote effective supervisory structures in these countries.

A crucial development in response to the G-7 call in Lyon was the formation of the G-10 Working Party on Financial Stability in Emerging Market Economies (Group of Ten, 1997), which was tasked with identifying and analyzing factors that promote financial stability in emerging economies. A major assignment of the Working Party was the outlining of a concerted international strategy to strengthen financial systems in such economies by promoting the establishment, adoption, and implementation of sound principles and practices conducive to financial stability.

Importantly, the Working Party explicitly acknowledged that multilateral institutions such as the Fund, the World Bank, and the regional development banks were an integral component of its strategy. The Fund, with its universal membership and the regular process of consultation with its members, had an important role to play in the international effort to promote the adoption and implementation of these principles and practices developed by the international groupings. The development and implementation of standards and codes in areas relevant to the effective functioning of a county's economic and financial system would come to represent key features of the concerted effort to strengthen the international financial architecture ${ }^{18}$.

In this context, Fund surveillance took on a specific function, in that it was given the task of analyzing whether or not inadequate applications of the principles and norms relevant for financial sector stability could have macroeconomic implications. Moreover, recognizing the importance of macro-financial linkages, it was emphasized that surveillance could help "to identify and draw the attention of national authorities to macroeconomic imbalances that can disrupt the banking and financial sector and to weaknesses in the financial sector that pose a risk to macroeconomic stability" (Group of Ten, 1997, p. 61).

The strategy proposed by the Working Party was endorsed by the G-7 at its Denver Summit in June 1997. Furthermore, the G-7 also urged national supervisors to implement the Basel Committee's Core Principles for Effective Banking Supervision, and called on the Fund and the World Bank to use such principles as benchmarks in their advisory activities and in conducting surveillance. Notably, the G-7 proposed that the IMF "give higher, targeted priority to financial sector stability in its surveillance work incorporating the guidelines and advice of the supervisory community" (Group of Seven, 1997).

\footnotetext{
${ }^{18}$ See Section III.
} 


\section{Box 2 - Strengthening Surveillance Through Better Data Provision and Transparency: The Data Dissemination Initiative}

On account of the role played by information deficiencies for Mexico's external liabilities in determining the 1994-95 crisis, the latter marked, inter alia, the beginning of a concerted effort on the part of the international community to improve the transparency and disclosure of macroeconomic and financial data.

Lack of transparency was deemed to be the single most critical factor in causing the Mexican crisis. In reviewing the factors underlying the crisis, the Fund highlighted the role played by some shortcomings in its surveillance activities, but at the same time emphasized that the crisis had clearly illustrated the adverse effects potentially resulting from lags in the provision of key information and data on a country's economic and financial situation. The Fund also questioned its own practice of relying almost exclusively on the member country for the provision of data and information about policies. It was acknowledged that such a practice could have had, at times, a negative bearing on the effectiveness of Fund surveillance.

In its April 1995 Report to the Interim Committee on Strengthening of Fund Surveillance (IMF, 1995d), the Executive Board underscored that strengthening the effectiveness of Fund surveillance was predicated on the regular and timely provision of data by all members. As a result, the June 1995 G-7 Halifax Summit expanded the scope of Fund's activities into the area of data provision and transparency, on the ground that "wellinformed and well-functioning financial markets are the best line of defense against financial crises" (Group of Seven, 1995).

In particular, in order to improve Fund surveillance and its early-warning capabilities, Fund members were asked to publish timely and reliable data on a broad range of economic and financial indicators, on the premise that improved transparency would minimize the occurrence of financial shocks. To this end, the Fund would have to:

- $\quad$ establish benchmarks for the timely publication of key economic and financial data;

- $\quad$ set up a procedure for the regular public identification of countries that comply with these benchmarks;

- $\quad$ insist on full and timely reporting by member countries of standard sets of data.

Following the identification by the Executive Board of a set of 12 core data categories, at its October 1995 meeting, the Interim Committee endorsed the establishment by the Fund of "standards to guide members in the dissemination to the public of their economic and financial data" (IMF, 1995f). The standards were to consist of two tiers: the Special Data Dissemination Standard (SDDS), to guide countries that have, or that might seek, access to international capital markets, and the General Data Dissemination System (GDDS), to assist all other member countries.

Following up on the inputs from the Interim Committee and the G-7, the Fund endorsed a two-pronged approach to improve the availability of comprehensive, high-quality, and timely macroeconomic and financial data for the purpose of surveillance. On the one hand, staff was instructed to more directly address issues regarding data availability to the Fund during the Article IV process, and to report more systematically to the Board the shortcomings in data provision. On the other hand, the Fund resolved to "develop without delay and implement data provision standards", and undertook the Data Dissemination Initiative ${ }^{19}$, centered on the establishment of standards to guide members in the diffusion to the public of their economic and financial data. As a result, the SDDS was approved by the IMF Executive Board in March 1996.

Similar to the Mexican episode, and possibly more intensely, the Asian crisis underscored the detrimental consequences arising from a lack of data. In its 1998 review of such crises (IMF, 1998b), the Fund itself acknowledged that, with regard to some affected countries, "the Fund had been taken by surprise, as had been the financial markets, owing in part to the lack of access to requisite information" (IMF 2000a, p. 13, footnote 11).

The reasons for these data shortcomings differed across countries. In some cases data were not collected by the authorities, while in other cases data were available but turned out to be unreliable. In some instances,

${ }^{19}$ See IMF (2008e) for a recent review of the Data Dissemination Initiative. 
information was available to the authorities and requested, but their unwillingness to provide data to staff appeared to be the main problem.

All in all, the Asian crisis revealed forcefully that the effectiveness of surveillance depended critically on the provision of timely and transparent information by the authorities, and caused an acceleration of the international effort to develop appropriate standards of data provision and disclosure.

In order to strengthen the availability of data and to supplement the SDDS, the GDDS was introduced in December 1997 to assist all Fund members in developing their statistical systems. In support of these initiatives, in September 1996 the Fund had set up the Dissemination Standard Bulletin Board (DSBB) to provide users access to subscribing countries' economic and financial data and metadata (information on country statistical methods and practices), with the aim of facilitating cross-country comparisons. Following the 1998 Review of the Asian crisis, in April 1998 the Interim Committee (IMF, 1998c) requested the Fund to expedite its efforts to broaden and strengthen the SDDS so as to cover additional financial data, including net reserves, short-term debt, and indicators of the stability of the financial sector.

\section{The March 1997 Biennial Review of Surveillance}

The March 1997 Surveillance Review (IMF, 1997a and 1997b) provided the first opportunity to assess the progress in the Fund's coverage of financial sector issues against the "soul searching" innovations introduced by the previous 1995 Review, as a result of the expanded scope of Fund surveillance to promote sound banking systems.

After acknowledging that surveillance was paying increased attention to the "core" macroeconomic issues ${ }^{20}$, as exemplified by the heightened coverage of exchange rate policies, the 1997 Review singled out the developments in the banking and financial sector among the areas where the efforts to strengthen surveillance had been undertaken in 1995-96 "with greater and lesser degrees of success" (IMF, 1997a, p. 20).

For example, the vulnerability of emerging markets' banking systems to large and volatile capital flows, as well as the relationships between the fragility of such systems and the conduct of monetary policy, had constituted the key issues of Article IV consultations and International Capital Markets reports between 1995 and 1997.

Perhaps more importantly, the review underscored that Article IV reports had made significant efforts in covering a country's financial sector and related policies. In this context, the scope and nature of the coverage had differed depending on the state of development of the banking system and the magnitude of the problems.

Overall, while recognizing that surveillance had paid substantial attention to financial sector issues, the review admitted that some identifiable shortcomings remained, mostly related to the coverage of these issues and the candor of the language.

Firstly, it was pointed out that the coverage of financial sector issues in Article IV consultations appeared, in most cases, to have been of a backward-looking nature, with only rare examples of strong forward-looking judgments made by staff about the state of the financial system and the likelihood of a crisis. This hesitation, which hampered the capacity

\footnotetext{
${ }^{20}$ The questions of what are the core issues in Fund surveillance and to what extent attention should be paid to non-core issues will be discussed in Section IV, in the context of the 1999 Crow Report (IMF, 1999c).
} 
to detect potential risks at an early stage, was thought of as a reflection of the fact that the full magnitude of banking problems often emerges only with a lag. At the same time, the lack of forward-looking judgments was partly ascribed to practical limitations on the ability of an Article IV mission team to identify banking problems in advance (IMF, 1997a, p. 29).

Secondly, the language used in the reports made it difficult to infer the extent of the financial risks faced by a country, as staff reports, while in many cases pointing out problems in the financial sector, lacked sufficient differentiation for them to provide clear warnings of a potential crisis.

As remedial measures to the above shortcomings, the review suggested that the treatment of banking sector issues in staff reports would benefit from an effort to make the assessments more forward-looking, with a view to detecting emerging tensions at an early stage; besides, the use of a more candid language was deemed as necessary to help the reader differentiate country cases according to the relevance of the underlying problems in the financial sector.

The review also touched upon the focus of surveillance, an issue that would repeatedly take center stage in future discussions on the effectiveness of surveillance ${ }^{21}$. While acknowledging improved continuity and increased attention to core issues, the review noted that the effort to establish clear and firm priorities in the Fund's surveillance activities appeared to have been less successful. In fact, despite such an effort, the trend had generally been in the direction of adding activities and initiatives, "while neither making cuts elsewhere nor increasing staff resources" (IMF, 1997a, p. 30).

Against this background, it is worth underscoring that the gradual increase in the Fund's coverage of financial sector issues as a result of the Mexican crisis becomes clear if one looks at the changes in the content of the 1995 and 1997 Staff Operational Guidance Notes for surveillance. While the previous such notes had made no explicit references to the need of covering financial sector issues, the 1995 Operational Guidance Note (IMF, 1998e) stated that:

"where appropriate, reports will include assessments of financial market developments and their implications for macroeconomic policies and performance" (IMF, 2000a, p. 83).

The 1997 Staff Operational Guidance Note went even further, recommending that:

"reports should include assessments of financial market developments and prospects as well as of problems and policy issues in the banking and financial sector where they are of macroeconomic significance" (IMF, 2000a, p. 86).

\section{Toward a Framework for Financial Stability}

In the aftermath of the Mexican crisis, among the first responses to the calls from the international community and the Interim Committee for strengthening the Fund's FSS, in

\footnotetext{
${ }^{21}$ On the effectiveness of surveillance, the review emphasized the multifaceted nature of the process: "the point is that surveillance is a process with a number of components, which interact in different ways at different times, depending on the issues at hand, the sequence of events and other factors" (IMF, 1997a, p. 20).
} 
March 1996 the Board held a topical seminar on the linkages between banking system soundness and macroeconomic policy (IMF, 1996a).

Recognizing that "the condition of the financial sector had elicited little attention at the macroeconomic policy level until recently" (IMF, 1996a, p. 1), the discussion built on a string of staff papers grounded on the fact that three-fourths of the Fund's member countries, in the past fifteen years, had experienced problems in their banking sectors ${ }^{22}$. Apart from provoking negative economic consequences, these crises had displayed an increasingly international nature, with costly spillover effects for the global economy and the international financial systems.

A major difference between these more recent staff papers and those issued in the 1980s (discussed in paragraph II.A) was a more forceful emphasis on the two-way linkages between macroeconomic policy and the stability of the banking system.

In fact, on the one hand, staff underscored that macroeconomic conditions and policies are a major component of the framework of policies and structural elements that are required to maintain the soundness of the banking system as a whole. While recognizing that bank soundness is first an issue for individual banks, it was pointed out that it is more likely to become systemic when unsoundness is due to macroeconomic conditions, because all banks are simultaneously exposed to those same risky conditions (Lindgren et al, 1996, p. 39).

On the other hand, it was recognized that weaknesses in the banking system can not only have important real effects for the economy, but can also constrain the formulation and effectiveness of macroeconomic policies and policy instruments ${ }^{23}$. In this regard, one of the main conclusions of staff"s analyses was that "the promotion of a sound banking system represents a legitimate policy objective, as well as a constraint, in the design of stabilization policies and structural reforms" (Lindgren et al, 1996, p. 161).

The Board seminar stood out for two reasons: it allowed staff to sketch out for the first time the main elements of a framework for sound banking, and it provided the opportunity of making suggestions on how to integrate banking stability issues into Fund surveillance, the design of Fund-supported programs, and the Fund's technical assistance.

In particular, the framework for sound banking outlined by staff was comprised of two main pillars: a supportive institutional environment; and a network of control structures.

\footnotetext{
${ }^{22}$ The internal policy papers were collected in the volume by Lindgren et al. (1996).

${ }^{23}$ For example, in the context of stabilization policies, concern for the soundness of the banking system can bring to the surface trade-offs in the choice of policy objectives and program targets. This is particularly true for monetary policy, as the banking system is the primary conduit for transmitting monetary policy signals. It is also worth noting that in staff's opinion the dual relationship between macroeconomic policies and banking system weaknesses had become more transparent with the internationalization of the financial system, as banks faced greater exposure to credit and market risks. This could complicate the conduct of economic policy, as "banking system soundness objectives ... should be added to the well known policy dilemma of how to balance monetary, exchange rate and fiscal policy objectives in the context of an open capital account" (IMF, 1996a, p. $13)$.
} 
The institutional environment was defined by the structural characteristics of the banking industry, notably an appropriate degree of competition, and a legal system that facilitates the enforcement of financial contracts.

The network of control structures was meant to consist of three components: the internal governance of individual banks (which staff singled out as the most important ingredient for sound banking); market discipline; and the official regulation and supervision at the domestic and international levels. Notably, an appropriate regulatory and supervisory framework was deemed by staff as critical to compensate for failures in internal governance and market discipline (IMF, 1996a, p. 14).

As far as the role of the Fund was concerned, there was awareness that "the Fund's surveillance role clearly ... [could not]... be as a banking supervisor, but as an advisor on policy" (IMF, 1996a, p. 22). Accordingly, along with Fund-supported programs and technical assistance, surveillance should be used as a vehicle to strengthen banking supervision and the financial systems across the Fund's membership, as well as to promote the adoption, at the international level, of standards and best practices for financial sector reporting, regulation, and supervision.

A crucial step in this regard was taken by the Interim Committee at its meeting of September 1996, with the adoption of the Declaration on "Partnership for Sustainable Global Growth" (IMF, 1996b). After acknowledging that Fund surveillance was an integral part of the strategy, the Declaration explicitly underscored the role of the Fund in the promotion of sound banking systems, notably through strong prudential regulation and supervision, in order to maintain macroeconomic stability and sustained growth.

\section{A Framework for Financial Stability ${ }^{24}$}

While the March 1996 seminar provided a basis for a broader discussion on the role of the Fund in FSS, it was clear that additional work needed to be done "to develop a set of indicators and an operational framework that... [would]...help Fund staff identify and evaluate current and prospective conditions of a banking system and their interface with macroeconomic and structural policy" (IMF, 1996a, p. 23).

The 1997 Surveillance Review took the discussion one step forward as it pointed out that "the approach to increased Fund involvement...[in financial sector issues]...would benefit from clearer specification" (IMF, 1997a, p. 30).

Fund staff was thus well aware that, in order to effectively enhance the Fund's coverage of financial sector issues, it would be useful to have a framework of general principles, characteristics, and best practices of sound and stable financial systems, based on a generally agreed body of knowledge and experience. This framework would help make Fund

\footnotetext{
${ }^{24}$ See also Schinasi (2006) for a more recent study on the development of a comprehensive framework for safeguarding financial stability. The author notes that "the practice of financial-stability analysis is still in its infancy when compared with, for example, the analysis of monetary stability or macroeconomic stabilitty" ( $\mathrm{p}$. 2).
} 
surveillance as effective, consistent, and transparent as possible, and it would also allow staff to effectively discuss appropriate remedial measures with member countries' authorities.

Against this background, it is perhaps no coincidence that on the very same day of the discussion on the 1997 Surveillance Review, the Board also discussed the paper "Toward a Framework for Sound Banking", which marked a signpost for the Fund's involvement in financial sector issues ${ }^{25}$.

The starting point of the framework was the recognition that national authorities have the primary responsibility for putting in place the necessary preconditions for a sound financial sector, notably macroeconomic stability and an appropriate regulatory and supervisory framework. At the same time, it was clearly acknowledged that the Fund and the international community also had significant roles to play, since banking crises could have macroeconomic consequences of a systemic nature, and could generate significant regional and international spillovers.

The Fund's actions to support the initiatives of many of its country members to promote the stability and soundness of their banking and financial systems were thus seen as part of a concerted global effort undertaken by international financial institutions and "standard setters" 26 to complement national initiatives and ultimately reduce systemic risks.

The universal membership of the Fund and its mandate to promote macroeconomic and exchange rate stability placed the institution in an optimal position to contribute to such an effort, notably through its surveillance activities ${ }^{27}$. In fact, the Board explicitly stated that the Fund's contribution to strengthen its member countries' financial systems should primarily take place "by enhancing the Fund's surveillance to cover developments in their banking systems, particularly where they exhibit problems with potential for generating serious macroeconomic disturbances" (IMF, 1998a, p. 5).

\footnotetext{
${ }^{25}$ The paper was renamed "Toward a Framework for Financial Stability" (IMF, 1998a)in July of the same year, following the publication of the Core Principles on Banking Supervision in April 1997, which were included as an Annex to a published version of the Framework paper. The name change was made to implement an invitation from the Basel Committee on Banking Supervision (BCBS) to the Fund and the World Bank (and to other international bodies) "to use the Principles in assisting individual countries to strengthen their supervisory arrangements in connection with work aimed at promoting overall macroeconomic and financial stability". It is worth noting that the Fund had been supportive of the development of international banking standards and best practices for some time, and had been strongly in favor of the Core Principles from the beginning. In this regard, the BCBS acknowledged that the Fund's call for international banking guidelines was an impetus for the development of the Core Principles (IMF, 2000d, p. 7).

${ }^{26}$ Standard setters are fora for international cooperation among regulators, supervisors, and industry groupings. The main standard setters are: the BCBS; the Committee on Payment and Settlement Systems (CPSS); the Financial Action Task Force (FATF); the International Auditing and Assurance Standards Board (IAASB); the International Accounting Standards Board (IASB); the International Association of Insurance Supervisors (IAIS); the International Federation of Accountants (IFA); the International Organization of Securities Commissions (IOSCO); the Organization for Economic Cooperation and Development (OECD); and the United Nation Commission on International Trade Law (UNCITRAL).

${ }^{27}$ In addition to increased surveillance, the efforts to strengthen the banking systems and to deal with outright banking crises had become a regular feature of Fund-supported adjustment programs in some countries. Besides, Fund technical assistance had helped to strengthen the financial infrastructure of many countries through advice on several areas of interest.
} 
In particular, two reasons were deemed to make surveillance a major instrument at the Fund's disposal for promoting financial sector soundness: on the one hand, the continuous nature of surveillance made it well-suited to monitor and support the efforts by the member countries' national authorities to improve the stability of their banking systems; on the other hand, the conditionality applied to the use of Fund resources could be used to ensure that weaknesses in these banking systems would be dealt with in a timely and effective fashion.

The proposed framework for financial stability was grounded on a number of relevant factors (Box 3). However, two important caveats were in order. Firstly, staff correctly pointed out that "in the end...Fund surveillance will not be able to certify financial systems as 'sound' or even reliably identify all instances in which difficulties in the financial sector may become a major macroeconomic concern" (IMF, 1998a, p. 4).

Secondly, the proposed framework should clearly not be seen as "a checklist of issues to be explored in every Article IV consultation, nor is it a diagnostic tool that could allow an assessment of the financial position of individual banking systems" (IMF, 1998a, p. 4).

Rather, the objectives of the framework were to increase the awareness of vulnerabilities in the financial sector and their potential consequences, as well as to recommend appropriate remedial measures. Ultimately, the framework would provide "guidance for the direction in which supervisory structures and financial system reforms should progress" (IMF, 1998a, p. 4).

\section{Box 3 - The Reasons to Build a Framework for Financial Stability}

The rationales for building a framework for financial stability were manifold:

- in bilateral surveillance, it would provide Fund staff with a broad guide for analyzing banking systems and identifying key areas of vulnerability;

- it would suggest several broad categories of issues that staff needed to be aware of in preparing for the discussion of financial sector issues with potential macroeconomic importance, in the context of the Article IV consultations;

- it would help in defining areas where corrective policies were called for, and in providing guidance for policy discussions with authorities;

- it would make the analysis and policy discussions more consistent and transparent across the Fund's membership; and

- in multilateral surveillance over the global financial system, a consistent application of the framework to systemically important countries could help identify financial problems and risks that have a potential for spilling over regionally or internationally.

The proposed framework identified five challenges that could undermine the soundness of the banking system:

- $\quad$ inadequate bank management;

- lack of adequate information on the financial conditions of banks, as "the opaqueness of banks' financial data is the Achilles' heel of effective corporate governance, market discipline, and official oversight in banking" (IMF, 1998a, p. 8);

- $\quad$ the presence of implicit or explicit public sector guarantees of bank liabilities (the official safety net);

- $\quad$ an ineffective bank supervisory environment; and

- concentrated bank ownership and connected lending. 
To overcome the above vulnerabilities, the following remedial measures were suggested: raising the competence and integrity of management; increasing the transparency of banking; limiting public sector distortions; controlling risk through regulatory and supervisory oversight; strengthening the broader structural framework of the banking system; and fostering national and international supervisory coordination.

In discussing the paper, the Board set a few conditions for developing and implementing the framework for the Fund's surveillance on the financial sector.

Firstly, the Board cautioned that due regard be paid to the circumstances of individual member countries. Staff was thus asked to be sensitive to different priorities for the adoption of international best practices, on account of the member countries' different traditions, existing structures, and resource constraints (IMF, 1997c).

Secondly, coverage of financial sector issues in Fund surveillance would need to follow a selective approach, along three dimensions:

- concentration on the banking system, since banks are likely to play a critical part in propagating financial crises, given that they are usually the dominant type of financial intermediary and are at the core of the domestic payments system. However, noting the increasingly blurring lines, in many countries, between the banking sector and other parts of the financial system, staff was aware that "in certain cases the Fund could extend its analysis and surveillance to such parts if there were difficulties with potential macroeconomic consequences" (IMF, 1997c);

- initial focus on countries in which banking sector issues were likely to have significant domestic macroeconomic concerns or systemic implications for the international financial system; and

- focus on the linkages between the safety and soundness of the banking and financial system and macroeconomic policies and developments. In this regard, it is worth mentioning that the availability of a framework for sound banking was explicitly intended to be instrumental in ensuring that macroeconomic risks were adequately reflected in prudential supervision and regulation.

Finally, the framework to strengthen Fund surveillance of the banking sector should be developed in a cost-effective manner, notably by seeking cooperation with other multilateral institutions and drawing on their expertise. In particular, indispensable input into the formulation of the framework should come from the standard setters, in particular the $\mathrm{BCBS}^{28}$.

These standard setters had been formulating a set of best practices, principles, and guidelines that experience had shown to be particularly important for creating an environment and an incentive system conducive to a sound financial system.

As a result, it was clear that one of the major synergies of the Fund's increased focus on banking and financial sector issues would be represented by its contribution to the

\footnotetext{
${ }^{28}$ The BCBS had been especially important in enhancing prudential control by formulating banking standards for large international banks, and these standards were increasingly seen as having applicability beyond the G10 countries.
} 
dissemination of such standards and best practices, their adaptation to the varying circumstances of its wider membership, and ultimately to the international harmonization of financial policies and practices ${ }^{29}$. With particular reference to the area of prudential standards, where the Fund had no regulatory or supervisory role, its effort would be complementary to that of the Basel Committee in that the best banking practices developed by the Committee would provide guidance for Fund surveillance and technical assistance.

Apart from illustrating the conceptual aspects posed by the new framework for financial stability, the Board discussion was also the occasion for a preliminary assessment of the impact of the Fund's increased involvement in the financial sector on the practical conduct of surveillance. In this regard, there was awareness that existing Fund practices in the context of Article IV consultations would necessarily evolve in a gradual way, partly on account of the limitations in the staff's expertise with financial sector problems. Staff reports and background papers were expected to reflect the increased emphasis on banking and financial sector issues, and Article IV discussions would represent the natural vehicle for the Board to be informed on the staff's assessment of macroeconomic issues arising from developments in a member's banking system.

The Board discussion on the framework for financial stability laid the ground for the development of the first Guidance Note for the Fund's FSS (IMF, 1998e), which would be released in June $1998^{30}$.

\section{E. Lessons from the Asian Crisis: the March 1998 Review}

Two and a half years after the Mexican crisis, another consequential event shook the international financial community. Following the devaluation of the Thai bath on July 2 , 1997, the speed and magnitude with which the Asian crisis spread across the region took virtually all observers by surprise.

At the height of the Asian crisis in March 1998, the Fund carried out a preliminary internal review of its surveillance in the affected countries, in particular Thailand, Indonesia, and Korea (IMF, 1998b). This work was conducted using as a benchmark the lessons from the Mexican crisis identified in the 1995 Surveillance Review and the Whittome Report, namely the provision of information and data availability, the continuity, clarity, and candor of surveillance, and its focus.

On continuity, while admitting that more continuous contact in the first half of the 1990s might have improved staff's ability to understand fully economic developments in the region and enhanced the Fund's effectiveness in alerting the authorities to the potential risks, the

\footnotetext{
${ }^{29}$ At the same time, a sort of "Fund specificity" was pointed out in its coverage of financial sector issues. The experience with financial system problems during the past decade had suggested the need for FSS to address some issues that had not been fully covered by the various expert groups. In particular, the existing body of best practices, principles, and guidelines could in some instances cover broader aspects of the financial system than those that generally are the subject of bank supervision, as well as they could require modifications to take into account the circumstances of some of the Fund's members.

${ }^{30}$ See Paragraph III.C.
} 
Review underscored that by 1995-96 several Southeast Asian emerging market economies had been the subject of fairly intensive scrutiny by the Fund in both bilateral and multilateral surveillance. Moreover, as staff concerns mounted, the frequency of contacts increased including at the level of management and senior staff.

On focus, the review candidly recognized that "... with hindsight, it is probably fair to say that in some countries Fund staff might have focused more on financial sector developments in 1993-95" (IMF, 1998b, p. 32).

This less than intensive coverage of financial sector issues in the first half of the 1990s was attributed to the fact that Fund surveillance over Southeast Asian economies was mostly concerned about their macroeconomic policy mix, notably the risk of overheating and the extent to which the mounting current account deficits reflected excess demand pressures.

At the same time, the review also emphasized that the post-Mexico expanded scope of Fund surveillance had resulted in an increasingly more intensive coverage of financial sector developments. In fact, the vulnerability of the financial sector and the risks it posed for the economy had increasingly represented the focus of Article IV consultations with some countries hit by the crisis, and the Fund had called for a strengthening of banking supervision and regulation (IMF 1998b, p. 16).

The review however also recognized that "Fund missions were sometimes not fully aware of the scale of these financial sector problems" (IMF, 1998b, p. 3). This relatively lower attention to financial sector issues in some Article IV discussions was accounted for by a combination of factors.

Firstly, and again, a lack of full information or unwillingness on the part of some authorities to engage in an open dialogue on the issues "...[hampered]...financial sector analysis...[and]... may have led to an underestimation of the extent of financial sector vulnerability" (IMF, 1998b, p. 4). This tempered staff's ability to better convey to the authorities the potential risks posed by current policies. Secondly, financial sector issues had grown in complexity in parallel with the rapid expansion of international capital markets, but staff analysis had been weighed down by a shortage of human capital with financial sector expertise on some Fund missions. Finally, Fund surveillance had to cover an increasingly broad spectrum of topics with the authorities, and the intensified focus on financial sector issues had only started in 1995.

\section{Five Key Lessons from the Asian Crisis}

The review was clear in underscoring that, despite the incorporation into surveillance practices of many of the lessons drawn from the Mexican episode, the Asian crisis had revealed several areas in which further efforts were required in order to ensure a fuller integration of financial sector issues into Article IV surveillance.

Five key lessons were thus drawn:

- the effectiveness of surveillance depends critically on the provision of timely and transparent information by the authorities (as discussed in Box 2);

- the crucial role of credibility and the restoration of market confidence in the Asian crisis underlined the importance of policy transparency. The loss of confidence that 
precipitated the crisis in a number of countries had proven all the more difficult to restore where markets doubted the coverage and candor of information provided by the authorities;

- $\quad$ in an environment of increased financial and trade flows between countries, Fund surveillance at the country level should pay more explicit attention to policy interdependence and the risks of contagion. The impact of policies in systemically or regionally important countries on other economies needed to receive constant attention $^{31}$;

- the effectiveness of Fund advice in the context of surveillance would benefit from supportive peer pressure, and it could be useful to gain more involvement by the Fund in regional fora;

- with particular regard to the focus on surveillance, in light of the clear role played by developments in the financial sector in making many of the affected Asian economies vulnerable, the key lesson drawn by the review was that such a focus would need "to extend even further and more deeply beyond the core short-term macroeconomic issues" (IMF, 1998b, p. 4). The Fund became thus aware of the need for " $a$ closer examination of the functioning of the financial sector... [in member countries]... at a much more detailed level than was previously required (IMF, 1998b, p. 36).

To this end, the Fund's FSS would have to encourage its members to take steps in four main $\operatorname{areas}^{32}$ :

- improving the regulation and prudential supervision of the banking system, in order to increase the capacity in central and commercial banks to assess and manage risks;

- developing domestic capital markets to better intermediate savings;

- improving the efficiency of the financial sector, including through the adoption of transparent accounting standards for corporations and efficient domestic bankruptcy codes; and

- limiting financial sector safety nets, for example through an explicit definition of the scope of deposit insurance, and strong conditionality associated with the provision of lender-of-last-resort assistance.

\section{Financial Sector Surveillance in the Aftermath of the ASian Crisis}

The role played by financial vulnerabilities in precipitating the Asian crises and the significant economic costs suffered by the affected countries laid the groundwork for an

\footnotetext{
${ }^{31}$ In this respect, there was scope for integrating more fully the Fund's multilateral surveillance in the ongoing bilateral dialogue with its members. This integration could be achieved by improving the extent to which the available expertise on capital market issues is disseminated within the Fund. Interestingly, it was pointed out that such dissemination would "both attune the staff and the Board more to financial market developments and risks and encourage much-needed human capital development" (IMF, 1998b, p. 36).

${ }^{32}$ IMF (1998b, box 5, p. 37).
} 
unprecedented effort on the part of the international community to enhance the international financial architecture. The year 1998 set itself apart in that it marked the moment when broad agreement was reached on a number of key aspects of the overall strategy put in place at the international level, and on the supporting role of the Fund.

In this context, it is worth emphasizing that Fund surveillance took on a crucial function, as it came to represent the mechanism through which the results of many of the initiatives to reinforce the international financial system would "come together... and filter" into the Fund's assessment of individual countries and, more generally, of the global economy (IMF, 2000a).

To intensify surveillance on its member countries' financial sectors, the Fund undertook a two-pronged strategy: on the one hand, it became all the more important to strengthen cooperation with other international organizations, notably the World Bank and various standard setters, in order to draw on their specific expertise. On the other hand, it was necessary to develop new instruments and analytical tools to deal more properly with financial sector issues.

In this regard, the development and implementation of standards and codes came to represent a key feature of the concerted effort to strengthen the international financial architecture. This effort culminated in the introduction of the joint IMF-World Bank Financial Sector Assessment Program ${ }^{33}$, which also marked a crucial step toward the Fund's involvement in FSS.

\section{A. Strengthening International Cooperation}

Since the Mexican crisis, the Fund and the international community became immediately aware that the expansion of the scope of Fund surveillance to cover financial sector issues would have important operational consequences for the conduct of surveillance, in terms of existing practices, staff expertise, and closer cooperation with other international organizations. Such cooperation stood out as particularly important to ensure an efficient division of labor, and to help address the constraints arising from the limited availability of the Fund's resources and expertise in financial sector issues.

Closer collaboration between the Fund and other international organizations, "to ensure that each focused on its area of comparative advantage" (IMF, 1997c) had already been called for by the Board in supporting the development of a framework for financial stability (Box 4).

In the same vein, the 1997 Report of the G-10 Working Party on Financial Stability in Emerging Economies, noting several overlaps in the roles and responsibilities of the Fund and the World Bank, had emphasized the importance of close coordination between them for the assessment of a country's financial conditions, program design, and technical assistance.

As part of the implementation of the Working Party's strategy, the two institutions had thus been asked to take "further steps to define their respective roles and means of coordination,

\footnotetext{
${ }^{33}$ Section III.D.
} 
both between themselves and with other international organizations" (Group of Ten, 1997, p. 69). In particular, the Fund and the World Bank were asked to develop "modalities for sharing their assessments of financial sector strength and of the regulatory and supervisory regimes in individual countries" (Group of Ten, 1997, p. 61).

The need for the Fund to rely on outside expertise was also echoed by the finance ministers and central bank governors of the Group of Twenty-Two in the October 1998 Report of the Working Group on Strengthening Financial Systems (Group of Twenty-two, 1998b), which explicitly recommended that "financial sector surveillance be anchored in the IMF's surveillance process but benefit from expertise at the World Bank and elsewhere" (Group of Twenty-two, 1998b, p. ix).

The report's starting point was that the Fund's Article IV process, while representing an established surveillance mechanism with an almost universal coverage, had not included, up to that time, financial sector stability as an integral part of the process. In acknowledging that "the scope of the surveillance process... [was]...being extended to cover this area insofar as it...[had]... a bearing on macroeconomic stability, and particularly to cover the banking system" (Group of Twenty-two, 1998b, p. 44), the Working Group recognized that, on the one hand, the Fund lacked the resources and expertise to conduct FSS alone, while, on the other hand, the World Bank had greater resources and expertise in this field, but its country coverage was limited.

Against this background, a major development in fostering international cooperation in the financial area was the publication, in September 1997, of the "Core Principles for Effective Banking Supervision" by the BCBS (1997) ${ }^{34}$. This also marked a key point for Fund surveillance, as the Basel Committee explicitly called for an involvement of the Bretton Woods institutions by suggesting that "the IMF, the World Bank, and other interested organizations use the Principles in assisting individual countries to strengthen their supervisory arrangements in connection with work aimed at promoting overall macroeconomic and financial stability" (BCBS, 1997 p. 2).

\section{Box 4 - Strengthening the Collaboration between the IMF and the World Bank on Financial Sector} Issues

The roles of the Bank and the Fund had historically been guided by their respective mandates and by the principles for cooperation set out in the 1989 Joint Memorandum on Bank-Fund Collaboration in Assisting Member Countries (the Concordat). According to this Memorandum, the Bank is primarily concerned with the microeconomic aspects of financial systems in developing countries, and tends to emphasize their sectoral and developmental features; the Fund's involvement in financial sector issues, including through surveillance, relates primarily to the macroeconomic aspects of such issues.

Within this broad framework, it became important to specify better the level of collaboration and the division of responsibilities between the two institutions with respect to such aspects as:

\footnotetext{
${ }^{34}$ The Basel Core Principles are comprised of twenty-five basic principles that need to be in place for a supervisory system to be effective. They are intended to be minimum requirements, which in many cases may be supplemented by other measures designed to address particular conditions and risks in a country's financial systems. The Principles were updated in October 2006.
} 
- the early identification of financial sector weaknesses in individual countries;

- the division of responsibilities with respect to the restructuring of the banking system; and

- the coordination of Bank involvement in financial sector reform with Fund macroeconomic analysis and financial programming.

At the same time, it was pointed out that the roles of the Bank and Fund, though primarily complementary, must continue to overlap in some respects because of the interaction between the macroeconomic and developmental aspects of financial systems.

On the occasion of the April 1997 meeting of the Interim Committee, the Managing Director of the Fund and the President of the World Bank had issued a Joint Statement outlining the main elements of a framework for collaboration between the two institutions on financial sectors issues. Subsequently, the Fund Board discussed a paper (IMF, 1997d) jointly prepared by the staffs of such institutions, which spelled out the general principles of collaboration between the Bank and Fund as follows:

- ensuring the prompt identification of financial sector problems in all countries, with each institution normally taking the lead in its own areas of primary concern; and

- avoiding duplication of activity in areas of mutual interest.

It was envisaged that regular meetings between the management of both institutions would address unresolved issues in the coordination of financial sector activity in particular countries, as well as the overall strategies for Bank and Fund involvement in financial sector reform. The highest priority would be given to collaboration in crisis situations.

In this regard, the Fund was directed to give greater emphasis in Article IV consultations to the identification of vulnerabilities in the financial sector that could potentially have major macroeconomic implications, and it would suggest corrective policies. The Bank would continue to make assessments of the health and performance of the financial sector in developing countries as part of its economic and sectoral work, and in the context of its lending programs.

The general provisions for collaboration would also apply to the coordination of the financial sector aspects of the Fund's surveillance and the Bank's assessment activity in developing countries, with a view to avoiding unnecessary duplication and ensuring that potential problem cases were not overlooked.

In particular, in deciding whether or not to conduct a more detailed assessment on its own, the Bank would draw on the findings of Fund surveillance regarding potential vulnerabilities in a country's financial system. For its part, the Fund would normally limit its more in-depth evaluations of financial sector issues to countries where the Bank had not recently undertaken and was not about to conduct a detailed Financial Sector Assessment (FSA), drawing on the Bank's assessments in those circumstances.

In light of the international effort to implement internationally accepted standards and best practices in member countries' banking and financial sectors, as well as to ensure uniformity of approach across countries, Bank and Fund staff would agree on guidelines for evaluating whether or not national authorities implement financial sector policy frameworks consistent with such standards and best practices, and for identifying significant financial sector problems. Through periodic meetings with the Basel Committee, it was envisaged that the Bank and the Fund would jointly provide feedbacks on the implications of their assessments for the enhancement of international norms.

The Asian crisis provided a particularly difficult test for the effectiveness of the existing procedures for BankFund collaboration in assisting members to strengthen their financial sectors, as it exposed problems in operational coordination. In order to enhance the collaboration between the two institutions, in September 1998 the Boards of the Bank and the Fund established the Bank-Fund Financial Sector Liaison Committee (FSLC), comprised of senior staff from both institutions (IMF, 1998f). 


\section{B. The Standards and Codes Initiative}

The assessment of the observance of standards and codes devised by international standard setters has become an important element of the diagnostics of Fund surveillance. The adoption of standards and codes aims at promoting greater financial stability, at both the domestic and international levels, by strengthening the regulatory and supervisory frameworks of member countries and, more generally, their institutional environment (institutions, markets, and infrastructure).

One of the central ideas underlying the adoption of these standards and codes was that by comparing information on potential borrowers (both public and private) against agreed benchmarks, market participants would be able to better assess and differentiate country risks; in turn, this would lead to better-informed lending and investment decisions, thereby reducing the risk of financial distress and contagion.

It is also worth noting that the role taken on by the Fund in assessing the observance of standards and codes marked a significant development as far as political legitimacy is concerned. In fact, the greater political legitimacy and authority enjoyed by the Fund, as a formal universal international organization, allow an increased capacity to foster compliance with internationally recognized best practices (Porter, 2000).

A major stimulus toward the adoption of international standards and codes came from the Interim Committee, which in April 1998 explicitly encouraged the Fund and the Bank to accelerate their work on finding the most effective way, possibly through "new forms of joint collaboration" and drawing on "relevant outside expertise", to offer their members the best possible advice on strengthening the domestic financial systems.

In particular, noting that this goal would require "supervisory and regulatory frameworks consistent with internationally accepted practices...notably the Basel Committee's Core Principles..." (IMF, 1998c), the Committee called on the Fund to work with other institutions and organizations responsible for the development of standards and guidelines in these areas. Furthermore, the Interim Committee directed the Fund to consider, in the context of its surveillance activities, "how best...[it]...could assist in the dissemination of such standards to the membership and to encourage members to adopt them" (IMF, 1998c).

In this way, the Committee implicitly recognized that the mere development of such standards could not be sufficient to improve the stability and efficiency of international capital markets if standards were not reflected in the actual practices. In other terms, while market incentives could play a major role in encouraging practices that were consistent with international standards, it was clear that the public sector had to play a part in strengthening the incentives to adopt such standards.

Following up on the Interim Committee's call, in July 1998 the Fund's Executive Board held its first discussion on the relationship between Fund surveillance and international standards, (IMF, 1998d). The Board first reaffirmed a defining principle of the Fund's action, making it clear that the institution's terms of involvement would be strictly dictated by its comparative advantages.

To this end, the Board drew a distinction between core and non-core areas. In core areas, those of direct operational concern, the Fund had both the mandate and the technical 
expertise to play a lead role in the development, dissemination, and monitoring of the standards.

These core areas are made up of two categories, the first being the one where the Fund takes the lead, namely data dissemination, fiscal transparency, and monetary and financial policy transparency ${ }^{35}$. The second category consists of areas, notably banking supervision, in which other standard setters have the lead role in developing standards, but where the Fund could contribute through dissemination and monitoring in the context of its surveillance activities.

The Basel Core Principles Assessments (CPAs) represented a major step taken by the Fund (and the World Bank) in this regard ${ }^{36}$.

Parallel work on standards was being done by other players of the international community. A working group composed of finance ministers and central bank governors of G-22 countries recommended that the Fund prepare a "Transparency Report", i.e., a summary assessment of a country's degree of compliance with internationally recognized disclosure standards (Group of Twenty-two, 1998a). Considering the universality of its membership and the regularity of its consultations with national authorities, the Working Group recommended that the Fund, in the context of its Article IV consultations, prepare such a report.

The Fund agreed that tying transparency reports to the Article IV process would help ensure universality of application and uniformity of treatment, thus providing an effective link to surveillance and giving the Fund the opportunity to review regularly all members' progress in this area (IMF, 1999a, p. 16).

It is noteworthy that the G-22 working group recognized that a Transparency Report would not prevent financial crises from ever occurring, but would constrain the ability of national authorities to mislead market participants, thus enhancing their credibility; furthermore, such a report would highlight practices and policies that need to be improved, and would indeed provide an incentive to improve them. Overall, by means of all these channels, a Transparency Report could reduce the frequency of future crises and dampen their severity when they occur.

In October 1998, the Declaration of the G-7 finance ministers and central bank governors (Group of Seven, 1998b) took another step forward toward shaping the role of the Fund in the area of international standards and codes by endorsing the G-22's call on the institution to:

\footnotetext{
${ }^{35}$ Work in these areas had led to the elaboration of the Special Data Dissemination Standard, the Code of Good Practices on Fiscal Transparency, and the Code of Good Practices on Transparency in Monetary and Financial Policies.

${ }^{36}$ The two main objectives of the CPAs are: 1) assessing the adequacy of the legislative and regulatory framework for banks, and 2) determining whether supervisors have the capability of effectively supervising and monitoring the relevant risks taken on by banks. CPAs were initially used by Fund staff in the context of its technical assistance or as structural benchmarks for Fund-supported adjustment programs. Subsequently, at the 1999 Annual Meetings, the Interim Committee urged that the CPAs "....be embedded into regular surveillance activities". Accordingly, an increasing number of CPAs started to be carried out as part of the FSAP. Fund staff conducted the first assessment of the Basel Core Principles in February 1998. The Fund then participated in a working group set up by the BCBS in October 1998, with the task of writing a "Core Principles Methodology", which was endorsed by the BCBS in October 1999 and revised in October 2006.
} 
- monitor, in close co-operation with the standard setters, the implementation of these standards and codes as part of its regular Article IV surveillance; and

- publish, in the form of a timely and systematic "Transparency Report", the results of its monitoring of Fun members' compliance with standards and codes.

As a result, the Standards and Codes Initiative was jointly launched by the Fund and the World Bank in 1999. The standards relate to three areas recognized by the two institutions as relevant to the effective functioning of their members' economic and financial systems:

- policy transparency;

- financial sector regulation and supervision; and

- market integrity.

The Fund plays a key role in the standards and codes initiative, as it is directly responsible for setting and assessing standards in the core areas where it has relevant expertise and mandate, namely data dissemination; transparency of fiscal, monetary, and financial policies $^{37}$. It also assesses the compliance with the Basel Core Principles for Effective Banking Supervision ${ }^{38}$.

The assessments of the degree of implementation of these standards and codes are undertaken by member countries on a purely voluntary basis. Their results are included in the Report on the Observance of Standards and Codes (ROSC), which thus provides an organizing framework for assembling the assessments of standards across a range of areas (FSF, 2000). ROSCs, in turn, are a key component of FSAPs, working as an input in judgments on vulnerabilities and development needs of a country's financial sector. As a result, the two initiatives, while distinct, are strictly interconnected.

It is worth noting that in discussing the ROSC, the Board made it clear that a transparency report should not be seen as " a checklist providing a simple pass/fail test of a members' observance of a standard" (IMF, 1999a, p. 16) ${ }^{39}$. Rather, this report would have to put the member's observance of standards in the appropriate context, by discussing the progress made by a country in meeting the standards and in describing its plans to further their adoption. As a result, each transparency report was intended to be "more a report on progress than an attempt to measure adherence against an absolute standard" (IMF 1999a, p. 16).

\footnotetext{
${ }^{37}$ The Financial Action Task Force (FATF) is the only other organization that produces financial assessments, namely in the area of anti-money laundering and combating the financing of terrorism (AML/CFT). The AML/CFT initiative was introduced in 2003.

38 Other important standards are the Core Principles for Systemically Important Payment Systems (SIPS), Objectives and Principles of Securities Regulation for the International Organization of Securities Commissions (IOSCO), and Insurance Core Principles (ICP) for the International Association of Insurance Supervisors (IAIS).

39 This clarification was in order also to reconcile the Fund's peculiar role as a confidential advisor to its members with the preparation and publication of such reports.
} 
In March 2000, the recently-established Financial Stability Forum ${ }^{40}$ endorsed the set of 12 key standards for sound financial systems identified by its ad hoc Task Force on Implementation of Standards (Financial Stability Forum, 2000), which was explicitly tasked with considering a strategy for fostering their implementation. The Task Force also underscored that the assessments of the adoption of standards and codes should be carried out as "partnership efforts" between the Fund, the World Bank, and standard setting bodies"

\section{The June 1998 Guidance Note for the Monitoring of Financial Systems Under Article IV Surveillance}

The number of initiatives to assist members in identifying potential vulnerabilities in their financial and supervisory systems led Fund staff to prepare the first Guidance Note for the Monitoring of Financial Systems under Article IV Surveillance (IMF, 1998e).

The Guidance Note explicitly directed staff to focus on the linkages between the safety and soundness of the banking and financial system and macroeconomic performance. The scrutiny was mandated to be particularly intense in case of financial system problems that could pose systemic risks for the economy.

Such a note stood out as it was the first operational tool at staff's disposal to assess in a comprehensive way the health of a country's banking sector in the context of Article IV surveillance. Importantly, the Guidance Note stressed that "the monitoring of financial systems will be valuable even if there is little immediate cause for concern about their soundness" (IMF, 1998e, p. 4).

Staff was directed to assess the banking sector's regulatory frameworks and their ability to avoid that a disturbance to the economy causes severe financial distress for the sector as a whole. Staff and the authorities were also expected to discuss any potential development in the financial system that could affect monetary policy implementation, the fiscal outlook, and, ultimately, the growth prospects.

Against this background, the staff's work was divided in two categories:

- "essential tasks" to be performed in order to strengthen the monitoring of the financial systems during the regular Article IV consultations; and

- "actions" to be taken if there were a presumption of significant weaknesses or deteriorating conditions in the financial system.

\footnotetext{
${ }^{40}$ In October 1998 (IMF, 1998b), the G-22 Working Group on Strengthening Financial Systems saw considerable promise in the setting up of "a Financial Sector Policy Forum in which finance ministries, central banks, and regulatory and IFI representatives could meet to discuss international financial sector issues across functional levels, and with full inclusion of systemically important emerging markets". In February 1999 the G7 endorsed a proposal by Hans Tietmeyer, former president of the Bundesbank, to establish the Financial Stability Forum (FSF). The Forum brings together senior representatives of national financial authorities (central banks, regulatory and supervisory authorities and ministries of finance), international financial institutions, standard setting bodies, and committees of central bank experts. See also footnote 77.

${ }^{41}$ See IMF (2005c) for the latest review of the Standards and Codes Initiative, and IMF (2009h) for the recent introduction of partial, risk-focused updates for financial (regulation and supervision) ROSCs.
} 
In monitoring the financial system, the Guidance Note drew the attention of staff on the following aspects: conditions and developments in the banking and financial systems that may impinge upon macroeconomic conditions and policies; macroeconomic developments that may have detrimental effects on the financial system; and aspects of the institutional, legislative, supervisory, and prudential regulation frameworks that could entail risks for the soundness of the financial system.

The Note stressed that the process of strengthening the monitoring of financial systems was of an ongoing nature. This process would be gradual and selective, reflecting the need to build up the staff's expertise in financial sector issues. In this regard, it was acknowledged that staff was not expected to check all the proposed indicators, nor consider all the issues in the context of a single Article IV consultation. The need for selectivity and proper prioritysetting in applying the general approach to individual countries implied that staff would need to focus its efforts "on those cases where financial fragility would appear to have clear macroeconomic implications" (IMF, 1998e, p. 5).

The Guidance Note constituted the basis for the pilot format of the Financial System Stability Assessment (FSSA) developed by the Monetary and Exchange Affairs Department (MAE) in May 1999 (IMF, 1999b).

\section{The Financial Sector Assessment Program}

The Financial Sector Assessment Program (FSAP), introduced in May 1999 and jointly administered with the World Bank ${ }^{42}$, represents the most relevant step toward an in-depth involvement of the Fund in $\mathrm{FSS}^{43}$.

As previously mentioned, the Mexican and Asian crises provided crucial impetus to develop the FSAP, in so far as the international community called for more intense international cooperation to reduce the likelihood and severity of financial sector crises and cross-border contagion. Perhaps more importantly, such crises contributed to the recognition that despite the increasing attention paid by Article IV missions on financial sector issues, it was "not feasible to expect them to do the broad and in-depth assessments" (IMF, 1999b, p. 1) of Fund members' financial systems that were being requested by the international community to improve crisis prevention.

The origin of the FSAP dates back to the G-7 Birmingham Summit of May 1998, where a report from the G-7 finance ministers identified a "gap" in the international system with respect to the surveillance of countries' financial supervisory and regulatory systems (Group of Seven, 1998a). On the premise that enhanced surveillance in this area would help encourage national authorities to meet international standards and reduce financial risk, G-7

\footnotetext{
${ }^{42}$ The Fund is solely responsible for FSAPs in industrialized countries.

${ }^{43}$ The importance of the FSAP in the context of FSS would deserve a paper of its own. While this goes beyond the scope of our work, the interested reader is referred to the paper issued on the occasion of the latest Board review of the program and to the references therein (IMF, 2009f and 2009g), as well as to the IEO's evaluation report on the FSAP (IEO, 2006).
} 
ministers saw "an urgent need for a system of multilateral surveillance of national financial, supervisory, and regulatory systems".

In the October 1998 Declaration, the G-7 finance ministers and central bank governors took a step forward by establishing " a process for strengthened financial sector surveillance ... for monitoring and promoting stability in the international financial system" (Group of Seven, 1998b). This process was explicitly based on the Fund's regular Article IV surveillance, and would allow International Financial Institutions, working closely with international supervisory and regulatory bodies, to conduct a peer review of the national financial sectors and their regulatory and supervisory regimes "with all relevant information accessible to them".

For its part, the Fund's Executive Board first discussed the launch of the FSAP on a pilot basis in May 1999 IMF, 1999b). The program was built heavily on the diagnostic studies of Fund members' financial systems carried out by staff over the previous two decades, in the context of the technical assistance provided by the MAE, as well as during Article IV consultations, multilateral surveillance, and adjustment programs. These diagnostic studies had focused especially on the linkages between financial system soundness and macroeconomic policy, and on the policies that could avoid or lessen the likelihood and severity of financial crises.

Against this background, the Fund's MAE and the Financial Sector Practice of the World Bank, coordinated by the joint Financial Sector Liaison Committee, developed a format, based on the 1998 Guidance Note, for the Financial Sector Stability Assessment (FSSA), the document that summarizes the FSAP findings and is used as input into Article IV consultations $^{44}$.

In its April 2000 Communiqué, the newly-renamed International Monetary and Financial Committee (IMFC), the former Interim Committee, provided high-level political commitment and placed the FSAP at the center of the Fund's surveillance on the financial sector. The IMFC stated that FSAPs, together with ROSCs, would serve "as the primary basis for enhancing the Fund's monitoring of the financial sector in the context of Article IV surveillance" (IMF, 2000e).

\section{Objectives and Scope of the Program}

The FSAP aims to strengthen the monitoring and promote the soundness of Fund members' financial system; it rests on the idea that the identification of risks and vulnerabilities in the financial sector, and the implementation of corrective actions at an early stage, will enhance these systems' resilience to a crisis. From the beginning, it was recognized that the program

\footnotetext{
${ }^{44}$ FSAP reports typically are comprised of two parts. The first part contains an overall "summary assessment" of the strengths, short-term vulnerabilities, regulatory capacity, and medium-term risks of a country's financial system. This part includes a clear identification of required remedial actions, and recommendations on appropriate policy reforms and technical assistance needs. The second part consists of sections describing the detailed work supporting the overall assessment, including "detailed assessments" of observance of international standards, codes, and good practices.
} 
should given higher priority to "systemically important" countries ${ }^{45}$, although the criteria for scheduling country participation would seek to maintain a balanced mix of countries.

The FSAP provides a coherent and comprehensive framework for pursuing four fundamental objectives:

- identifying vulnerabilities of financial systems and determining how key sources of risk are being managed ${ }^{46}$;

- ascertaining the system's developmental and technical assistance needs;

- assessing the observance and implementation of relevant international standards and codes; and

- helping develop and prioritize appropriate policy responses.

The FSAP contributes to these objectives by providing the national authorities with a comprehensive and in-depth assessment of their financial systems (the previously-mentioned FSSA). To this end, the FSAP builds on a number of complementary analytical tools developed within the Fund in order to improve the quality and effectiveness of its assessments and to ensure consistent treatment among countries.

These tools include:

- the assessments of standards and codes used to evaluate institutional and regulatory structures (Box 5);

- the systematic analysis of Financial Soundness Indicators (FSIs) and stress testing used to identify risks and vulnerabilities ${ }^{47}$; and

- the assessment of the broader financial stability policy framework.

\section{Box 5 - Standards Assessments and the FSAP}

An important feature of the FSAP is that it represents the "primary vehicle" for the Fund and the Bank to prepare detailed "standards assessments", i.e., an evaluation of the extent to which countries have adopted and implemented internationally recognized standards, codes, and good practices in the financial sector, in such areas as financial sector regulation and supervision, bank resolution, payments, and settlements.

\footnotetext{
${ }^{45}$ Systemically important countries include "both countries whose capital markets intermediate the bulk of global financial transactions, and emerging countries whose financial system have the potential to cause, or be subject to, undue volatility in cross-border flows and financial system contagion”. IMF (2000g, p. 29).

${ }^{46}$ Coverage includes: (i) prudential regulation and supervision of banks and other financial intermediaries, including compliance with international standards, core principles, and good practices; (ii) financial policies, instruments, and market arrangements for liquidity management; (iii) systemic risks in payment systems; (iv) arrangements for crisis management, such as financial safety nets, frameworks for bank and corporate restructuring and bankruptcy; (v) market infrastructure, including disclosure and transparency practices; and (vi) vulnerabilities in financial institutions and markets to macroeconomic shocks, contagion, and consequences of financial vulnerabilities and reforms (possibly including stress testing and simulations). IMF (1999b, p. 3).

${ }^{47}$ See paragraph E and Jones et al. (2004).
} 
Standards assessments are grounded on the view that a high degree of observance is necessary for the stability of financial systems that are integrated into global financial markets and face a variety of financial innovations and shocks.

Standards assessments in the FSAP have served three purposes:

- identifying gaps in financial sector regulation and transparency practices in order to implement regulatory and operational reforms;

- providing input for the overall stability assessment of the financial system; and

- helping country authorities to evaluate their own systems against international benchmarks.

Based on the FSAP report, "summary assessments" of the observance of financial sector standards and codes are subsequently presented simultaneously: 1) as an input to formulate an overall stability assessment in the FSSA reports, and 2) as the "financial sector modules" in the broader ROSC.

It is important to note that the FSAP/FSSA process not only offers a vehicle for standards assessments but also provides "the proper context for assessment of observance of key financial sector standards" (IMF 2000g, p. 14).

In fact, early experience with the preparation of FSSAs indicated that the relationship between observance of standards and the stability of a financial system is a complex one. In fact, FSAP missions had found standards assessments not to be particularly helpful "in isolation" in identifying immediate risks and vulnerabilities or key developmental weaknesses.

As a result, in order for standards assessments to be effective, two important principles have to be met:

- selectivity and prioritization. The choice of which specific standards, codes, and good practices should be assessed, as well as the scope of these assessments, should be decided on a country-by-country basis, taking into account the country circumstances and the degree to which transparency and compliance issues are key to the assessment of risks and vulnerabilities ${ }^{48}$; and

- standards assessments "need to be combined with a broader range of information and analysis in order to obtain a... [country's]...complete picture of relevant risks and vulnerabilities required for an overall stability assessment, and the identification of development priorities" (IMF 2000g, p. 12).

Staff also underscored that the analysis of the summary standards assessments in the broad institutional, macroprudential, and policy framework provided in the FSSA is important as it highlights the contribution of standards observance to containing risks and vulnerabilities in the financial system, thereby fostering financial stability.

One of the most significant features of the FSAP is that it is a cooperative international effort. This enhances its legitimacy and is a source of "positive externalities". In fact, the participation in FSAP missions of outside experts from central banks, supervisory agencies, and international standard-setting bodies allows the benefits of the program to extend beyond the Fund's activities. These members of the international financial community are indeed able to better leverage their resources toward the common objective of strengthening the international financial architecture; they also provide an important element of international "peer review", especially in the assessments of the observance of international standards and codes of good practices.

${ }^{48}$ The Code of Good Practices on Transparency in Monetary and Financial Policies (MFP) and the Basel Core Principles for Effective Banking Supervision (BCP) are the standards usually assessed for all FSAP countries, although their coverage has varied depending on the structure of the financial system. When undertaking the assessments, the focus has been on assessing the quality of compliance and not simply on preparing a checklist of technical compliance. 
The case for close cooperation and involvement of external experts was a direct consequence of the resource-intensive nature of the FSAP, which made it imperative to optimize the use of scarce financial sector expertise, avoid duplication of efforts, and promote consistency of advice on financial sector issues.

Being an ambitious and complex exercise, some features of the FSAP continue to be the object of debate, most notably because they may have prevented the program from fully delivering its potential. Two such features are the comprehensive nature of the FSAP and its relationship with Article IV surveillance ${ }^{49}$.

\section{The Comprehensive Nature of the Program}

Ever since the pilot phase, a distinctive characteristic of the FSAP has been a sort of tension between its broadly "one-size-fits-all" nature, on the one side, and the necessary flexibility to adapt the program to country-specific factors, on the other. This tension is mainly a direct consequence of two opposing forces: the comprehensive nature of the program, which covers issues related to both the near-term stability of the financial system and its long-term developmental priorities; and the need for greater selectivity and prioritization in the scope of the assessments, given the intense resource requirements that the exercise places on the Bank and the Fund, as well as on the national authorities.

To mitigate the risk of a "one-size-fits-all" effect, staff developed "an approach to financial system assessment that is broadly consistent across countries, while allowing for differences in emphasis to reflect different country circumstances" (IMF, 1999b, p. 2). To this end, in developing the initial template for FSAP assessments, staff made it clear that "not every element of the template will be assessed in every case, nor will any of the elements be applied mechanically" (IMF, 1999b, p. 2).

Despite these guidelines, FSAP assessments during the pilot phase turned out to be generally broad in scope, and resulted in rather long reports covering all the main areas that could be included in a "full" FSAP assessment.

It soon became clear that this type of assessment would not be practicable in every country. Selectivity and prioritization were thus required for the FSAP process to be cost-effective for all the interested parties. Accordingly, it was understood that the scope of the assessment could vary so as to cover "those issues and institutional features which are judged to be most important for financial sector stability and development" (IMF, 2000g, p. 14).

At the same time, however, staff was aware that this selectivity principle should be applied with caution and should not be taken too far so as to preserve the integrity of the exercise. In fact, staff pointed out that "there will always be a need to maintain a fairly broad scope for...[FSAP assessments]...to ensure adequate consideration of the particular circumstances of individual countries and to avoid possible 'cherry picking' of the various components of an FSAP assessment that would undermine the quality of the assessment as a whole" (IMF, 2000g p. 14-15).

\footnotetext{
${ }^{49}$ See Section $\mathrm{V}$ for the most recent discussion on these two issues.
} 
A first move toward more selectivity and prioritization of the scope of the FSAP was made on the occasion of the 2003 Review of the program (IMF, 2003a). The guiding principle of such a streamlining drive was that FSAP assessments, while remaining comprehensive in areas relevant for financial stability and development, should be contained along three dimensions:

- the depth and intensity of the assessment of individual components of the FSAP should be better tailored to country-specific circumstances;

- the number of standards to be assessed in detail would typically be limited to an average of three per FSAP assessment, compared to the previous four to six; and

- for countries with complex financial systems, where the potential scope of the program is particularly wide, FSAP assessments should follow a two-stage approach: the first stage could cover a prioritized range of topics and standards, while the remaining topics and standards could be examined in the context of subsequent reassessments and updates.

Subsequently, as FSAP "updates", rather then full assessments, began to account for the bulk of the FSAP work, the 2005 Review of the program (IMF, 2005a) defined more clearly the scope and modalities of such updates by mandating that they contain a "minimum, core element", namely a stock-taking exercise assessing financial sector developments and progress in implementing FSAP recommendations.

\section{The FSAP as an Input in Article IV surveillance}

Ever since its inception, there was a clear awareness that follow up work on the FSAP findings and recommendations would be a critical task for the program to effectively help strengthen a country's financial system. This was clearly underscored by staff in noting that the assessments conducted under the FSAP are "diagnostic tools, not ends in themselves" (IMF, 2000g, p. 17).

The results of these assessments were indeed meant to form the basis for the adoption, on the part of national authorities, of measures to readdress the identified vulnerabilities and developmental needs of their financial systems. Follow-ups, largely in the form of technical assistance, were also viewed as essential to maintain the momentum for financial sector reforms and development.

It is important to underline that the issue of the FSAP's follow-up work takes on a dual dimension, being related to both the continuity of the exercise over the years and its role as an input in Article IV surveillance.

On the first dimension, given the voluntary nature of the program and the limited frequency with which full assessments could be undertaken, Fund staff was aware that in order to ensure continuity and maintain adequate monitoring of financial systems, it would be necessary to develop mechanisms for regularly updating the initial "baseline" FSAP assessment. To this end, the Board agreed that "focused updates" or "reassessments", together with work undertaken during Article IV consultation missions and off-site monitoring of a country's financial sector, would provide "a framework that can supplement 
the FSAP effectively, and thus enable more continuous and effective financial sector surveillance" (IMF, 2003b).

In particular, FSAP updates would cover key issues of systemic relevance identified during previous FSAP work, so as to take into account recent developments and new measures adopted by the authorities.

The second dimension is even more important as it relates to the fact that a crucial objective, perhaps the objective, of FSAP reports is to feed into and help strengthen the Fund's Article IV surveillance process, which is mandatory for all member countries.

The role of the FSAP as an input to surveillance has been a crucial feature of the FSAP since its inception. The program was indeed seen as "a vehicle to bring the linkages between financial sector soundness and macroeconomic developments to the core of both institutions' work" (IMF, 2000c, p. 3).

To this end, the FSAP envisaged a procedure ${ }^{50}$, centered on the FSSA, explicitly aimed at including FSAP findings in Article IV consultation discussions. FSSA reports were indeed seen to offer a major analytical advantage to make surveillance more effective, in that they placed the assessment of a financial system's risks and vulnerabilities in a broader macroeconomic and macroprudential context than had traditionally been the case ${ }^{51}$.

\section{E. The Development of Financial Soundness Indicators}

The introduction of the Report on Observance of Standards and Codes and the Financial Sector Assessment Program was the occasion for Fund staff to start developing the components of a broad framework for macroprudential analysis.

This drive was grounded on the notion that the monitoring of financial vulnerabilities would be best done on the basis of objective measures of financial system soundness, as well as of methods to analyze these measures. These were referred to as Financial Soundness Indicators (FSIs) and macroprudential analysis, respectively.

In particular, macroprudential analysis was seen as an additional tool, complementary to the use of other "early-warning" instruments, to help identify corrective actions and, ultimately, contribute to crisis prevention.

\footnotetext{
${ }^{50}$ Upon completion of the FSAP mission, a confidential note (aide-mémoire) is provided to the authorities. The joint FSAP report is discussed with the country authorities during the Article IV consultation that ideally takes place a few months after the FSAP mission. This discussion serves as the basis for staff to prepare the FSSA. Following the 2003 FSAP review, the main FSAP Report is no longer produced and has been replaced by a revised aide-mémoire, which the FSSA draws on. Bank staff separately prepares a FSA to be distributed to the Executive Directors for their information. While drawing on the joint FSAP report, separate FSSAs and FSAs enhance the accountability of the two institutions.

${ }^{51}$ In fact, a major strength of an FSSA is the use of a broad range of information drawn from such tools as FSIs, stress tests and scenario analysis, the assessments of observance of standards, the examination of a country's institutional setting, the regulatory environment, and the depth and diversity of the financial system. Besides, the FSSA serves as an input into the design of policy and structural benchmarks in Fund-supported programs, and it provides the basis for prioritizing and organizing technical assistance in the financial sectors.
} 
In this context, the Fund promoted the compilation and use of an internationally agreed set of FSIs , broadly defined as indicators of the health and stability of financial systems (IMF, $2001)^{52}$. FSIs were deemed as critical in producing reliable and comparable assessments of the strengths and vulnerabilities of member countries' financial systems as part of Fund surveillance, as well as in enhancing disclosure of key financial information to markets and strengthen market discipline.

FSIs are comprised of both macroeconomic variables associated with financial system soundness, and of aggregated micro-prudential indicators of the health of individual financial institutions, such as capital adequacy, nonperforming loans, liquidity, and profitability ${ }^{53}$.

The first step toward the development of FSIs was a consultative meeting of experts in September 1999, convened to elicit private and official opinions from outside the Fund.

Private sector participants favored the compilation of internationally agreed sets of financial indicators to facilitate cross-country comparisons, and concurred on the need to establish a process leading to greater harmonization over time. Furthermore, it was emphasized that the analysis of financial sector vulnerabilities could not rely on quantitative indicators alone, as qualitative information on institutional arrangements and informed judgments were also essential.

The comments received during this consultative meeting were incorporated in an Occasional Paper (Evans et al, 2000) on macro-prudential indicators and data dissemination issues, which was discussed by the Board in January 2000. To start off the process, a Survey on the Use, Compilation, and Dissemination of Macro-prudential Indicators was then undertaken by the Fund in mid-2000, designed in consultation with national authorities, international organizations, and the private sector. The survey revealed a strong, widespread, and largely unmet demand for FSIs, and led to a list of 56 macro-prudential indicators.

In discussing the survey, the Executive Board pointed to the need for selecting a smaller and more operationally useful "core" se of indicators intended to serve as a basis for structuring data work in support of financial system monitoring, including through the FSAP.

Based on six criteria ${ }^{54}$, in June 2001 the Board endorsed two key sets of FSIs (IMF, 2001):

- a core set of 15 FSIs that focus on the banking sector; and

\footnotetext{
${ }^{52}$ In early staff papers on the subject, FSIs were initially referred to as "macroprudential indicators". The development and possible dissemination of FSIs had been encouraged by both the G-7 and the IMFC. In its communiqué of April 28, 2001, the G-7 noted that "the Fund... should further its work in building up and publishing macroprudential indicators for the financial sector" (Group of Seven, 2001). In the words of a former director of the MAE, Mr. Stefan Ingves, "macroprudential analysis requires well-developed linkages between theory and practice, between supervisors responsible for individual institutions and central banks responsible for systemic stability, and between a wide variety of backward-and forward-looking indicators for financial sector health" (Hilbers et al, 1999, p. 296).

${ }^{53}$ For the banking system, the so-called CAMELS framework is a useful way to perform such aggregation. It involves the analysis of six groups of indicators: Capital adequacy, Asset quality, Management soundness, Earnings, Liquidity, and Sensitivity to market risk.

${ }^{54}$ Focus on core markets and institutions; analytical significance; revealed usefulness; relevance in most circumstances (i.e., not country-specific); availability; and parsimony.
} 
- an encouraged set of FSIs, consisting of additional indicators for the banking sector, as well as of indicators for the nonbank financial sector, the corporate and household sectors, and the real estate markets.

In its June 2001 discussion on FSIs, the Board also endorsed further work on FSIs in two key areas:

- the development of a "Compilation Guide" on FSIs by staff to encourage national authorities to compile and disseminate FSIs; and

- analytical work to enhance the role of FSIs in macro-prudential analysis.

It is worth noting that this analytical work had the explicit objective of strengthening macroprudential surveillance by integrating the analysis of FSIs with other surveillance tools, such as stress testing, and by clarifying the linkages among FSIs based on the accounting and lending relationships. It was indeed recognized that these linkages were especially important for the corporate and real estate sectors, given their potential to detect risks to the financial sector at an early stage.

Further progress on FSIs was made in recent years. In June 2003, the Board endorsed the conduct of a "coordinated compilation exercise - CCE" for FSIs by Fund staff, in collaboration with other international agencies (IMF, 2003c). The CCE was launched in March 2004 with a view to: (1) developing the capacity of the member countries to compile FSIs important to the surveillance of their financial systems, (2) promoting cross-country comparability of FSIs, (3) coordinating efforts by national authorities to compile FSIs, and (4) disseminating the FSI data compiled in the CCE, along with metadata, to increase transparency and strengthen market discipline ${ }^{55}$.

The FSI's Compilation Guide was posted on the IMF website in 2004, and published by the Fund in 2006, with the important goal of promoting comparability of FSIs between countries $^{56}$. In November 2007, the IMF Executive Board reviewed the experience with FSIs and supported regular collection and dissemination of FSIs by the Fund. A centralized public FSI database was created and became available to member countries, international institutions, and markets.

The composition of the sets of FSIs will be revised in light of the lessons drawn from the recent global financial crisis.

\section{Fund SURVEILlanCE UNDER AN EXPANDED SCOPE}

The string of initiatives put forward by the international community in the aftermath of the Mexican and Asian crises had resulted not only in the expansion but also in the increased complexity of the Fund's surveillance mandate.

\footnotetext{
${ }^{55}$ Sixty-two countries accepted invitations to participate in the CCE. In January 2007 the Fund posted on its website the finalized data and metadata for 57 countries.

${ }^{56}$ See "Financial Soundness Indicators (FSIs) and the IMF". Available at http://www.imf.org/external/np/sta/fsi/eng/fsi.htm
} 
The growing involvement of the Fund in somewhat uncharted territories associated with the more structured and systematic analysis of financial systems had eventually raised the need to take stock of the ways in which the new activities had been integrated with the institution's more traditional tasks.

To this end, in June 1998 the Board commissioned an evaluation of Fund surveillance under Article IV to a group of independent experts chaired by John Crow, a former Governor of the Bank of Canada.

To a large extent, the Crow Report (IMF, 1999c) marked the start of the second phase of the Fund's involvement in FSS, in that some of its findings contributed to lay the groundwork for the efforts put out by the institution to make progress on two interrelated issues that are being debated still today: how to more closely integrate financial and macroeconomic analyses in bilateral surveillance, and how to bring the coverage of the new areas of surveillance "up to par" with that of the more traditional ones.

\section{A. External Evaluation of Fund Surveillance: The Crow Report}

With regard to bilateral surveillance, one of the main findings of the "Crow Report" was that, although the quality of Fund analysis and advice in areas of core expertise (namely exchange rate policies and the associated macroeconomic framework) was generally highly rated, views were more critical in such areas as FSS and structural issues.

To explain the different opinions on the quality of the Fund's advice, the report pointed to a "fairly broad sense among interviewees that surveillance had become more difficult to do well, largely because of the expanded mandate to cover capital account and financial sector issues" (IMF, 1999c, p. 37).

Moreover, on the Fund's increased involvement in the surveillance of the financial sector, the report found a general agreement that "having the assessment of financial systems and their vulnerabilities become an integral part of Article IV consultations was highly appropriate" (IMF, 1999c, p. 39). Importantly, Fund's involvement in FSS was explicitly justified by "the close linkage - in both directions - between domestic financial sector crises and exchange rate/balance of payments crises" (IMF, 1999c, p. 67).

More generally, it was acknowledged that the expansion of Fund surveillance into financial sector and capital account issues was inevitable given the increased interconnectedness between such issues and the Fund's traditional analysis of macroeconomic and external sector issues.

However, the Report highlighted that the monitoring of the vulnerabilities of individual financial systems "...could not be taken to imply a permanent in-depth analysis of all the microeconomic aspects of various financial systems" (IMF, 1999c, p. 40).

A point worth noting is the Report's recognition that "improving financial sector surveillance was identified as an important task as long ago as 1995, and the pace of improvement has been slow" (IMF, 1999c, p. 67).

Similar to the findings of the March 1998 Review, this outcome was in part ascribed to a shortage of expertise in the financial area. In fact, it was clearly emphasized that, up to that 
point, the expansion of the scope of Fund surveillance to cover financial sector issues had faced difficulties of practical implementation, as "area departments have tended to treat this remit as another add-on, which they do not have the time and expertise to fulfill in more than a pro forma way, especially if countries drag their heels in providing information" (IMF, 1999 c, p. 40) ${ }^{57}$.

Against this background, the Report acknowledged that the FSAP, soon to be undertaken by the Fund, would help improve FSS. To this end, two important conditions were identified:

- the Fund would need to be able to draw on staff with financial sector expertise; and

- the financial sector analysis carried out in the context of the FSAP would have to be properly integrated into the Article IV process.

In the years following the Crow Report, the efforts to meet these conditions have figured prominently within the Fund's work on surveillance.

\section{B. The Macroeconomic Relevance Test}

The discussion on the Crow Report by the Board represented the first occasion to address a question that by that time had become crucial for the effectiveness of Fund surveillance under its expanded scope: how to strike the proper balance between the need for surveillance to cover a wider range of issues, while at the same time ensuring that individual Article IV consultations retain a clear focus on the key concerns in each country: in other terms, a balance between the breadth of coverage and the depth of analysis.

Maintaining a suitable focus of surveillance had come to constitute a challenge for the Fund in light of the string of initiatives undertaken by the international community, in the aftermath of the Mexican and Asian crises, to strengthen the international financial architecture. As a result of such initiatives, the issues identified in Fund surveillance as core had changed over time "from a narrow focus on exchange rate policy and the balance of payments and attendant monetary and fiscal policies to greater emphasis on capital account, financial sector, nonfinancial structural issues, and cross-country influences" (IMF, 1999c, p. 4).

This expanded agenda was a potential source of tension between the coverage and the focus of surveillance: on the one hand, the Fund was being asked to be comprehensive and cover a wider array of issues; on the other, it had to be more focused and selective in surveillance so as to improve the depth and quality of its analysis. The Crow Report itself had discussed the expansion of the scope and coverage of bilateral surveillance into structural issues of nonfinancial nature, as "there were concerns that this expansion of coverage in fact detracted from the effectiveness of surveillance overall" (IMF, 1999c, p. 13).

\footnotetext{
57 This judgment was broadly agreed upon by staff in its response to the Crow Report: "Notwithstanding the identification by the Fund's internal reviews of the need for more attention to [financial sector issues], we agree that implementation of these general principles has taken time. This can be explained, in part, by limited resources and, in some areas, expertise" (IMF, 1999c, p. 98).
} 
Accordingly, the key recommendation of the Report was to focus bilateral surveillance as much as possible on the Fund's core areas, namely exchange rate policies and the directly associated macroeconomic policies, including financial sector and capital account issues. Analysis outside these core areas should be undertaken "only if directly relevant to a particular case" (IMF, 1999c, p. 14) ${ }^{58}$.

To address the potential tension between coverage and focus of surveillance, the Crow Report suggested what would soon come to be known as the "macroeconomic relevance test": the criterion for addressing noncore issues in Fund surveillance should be "the extent to which they actively and directly impinge upon the effective conduct of macroeconomic policy" (IMF, 1999c, p. 63).

In discussing the Crow Report, the Board agreed on the need to revisit the definition of the core areas of surveillance. To sharpen its focus, a number of Directors favored a country-bycountry approach whereby "coverage of issues could differ depending on the circumstances of a particular country, but the staff would be expected to present a clear case for the consideration of any particular set of noncore issues as relevant to the core concerns of the Fund" (IMF, 1999c, p. 4).

This approach was further refined in the context of the March 2000 and the March 2002 Surveillance Reviews: while falling short of drawing a clearer distinction between core and noncore issues, it was agreed that the twin objectives of comprehensiveness and focus could only be achieved by ensuring that "selectivity of coverage is molded to country-specific circumstances" (IMF, 2002c).

Specifically, the coverage of surveillance should be guided by the following three principles:

- first, staff would need to be well-informed on the range of issues within the expanded scope of surveillance;

- second, within this range of issues, the selection of topics to be covered in discussions with members should derive from the application of the "macroeconomic relevance test", so that noncore issues would be covered "only when these have a direct and sizeable influence on macroeconomic developments" (IMF, 2000b); and

- third, within these selected topics, priority should be given to the matters at the apex of the "hierarchy of concerns" relevant for Fund surveillance, namely: external sustainability and vulnerability to balance of payments or currency crises; sustainable growth and the policies to achieve it; and, for systemically important countries, conditions and policies affecting the global and regional economic outlook.

Based on these principles, the Operational Guidance Note (IMF, 2002d) that followed the 2002 Review specified the core areas to be covered as including "exchange rate, monetary and fiscal policies, as well as financial sector issues".

\footnotetext{
${ }^{58}$ In this regard, the report found it important to emphasize that a more central focus on what might be considered the traditional core of surveillance did not mean that important linkages between macroeconomic management and other policies should not be recognized and addressed as part of surveillance.
} 


\section{Bringing Coverage of Financial Sector Issues "Up to Par" with Coverage of Other Core Areas of Surveillance}

To a large extent, the Crow Report marked the beginning of a new phase for the Fund's involvement in FSS. The Report had indeed helped to make it all the more clear that the expansion of surveillance to systematically cover financial sector issues was just a necessary but not sufficient condition to improve its effectiveness. This latter depended more fundamentally on how the expanded scope of surveillance would actually be implemented and translated into effective operational practices during Article IV consultations.

The existence of a sort of "implementation gap" was clearly acknowledged in the Crow Report in underlying that FSS still constituted a sort of "add-on" to the more traditional macroeconomic analysis that was at the core of Article IV consultations.

In order to close the gap between the strategic expansion of the Fund's surveillance agenda and the actual implementation of such an objective, the Crow Report pointed to the need to address "something of a disconnect (or at least a very long lag) between the broad policy directions outlined by the Board in review and policy discussions, and actual practice in dayto-day surveillance work, particularly bilateral consultations" (IMF, 1999b, p. 64).

It was thus no surprise that, for surveillance to become more effective, the Report recommended that the next internal review devote more attention to "measuring in some detail (by topic and country) the extent to which the specific operational guidance that has been put forward on behalf of the Board is actually followed in Fund consultation reports, and, equally important, if not, why not" (IMF, 1999b, p. 64).

To this end, the 2000 and 2002 Surveillance Reviews (IMF, 2000a, 2002a, and 2002b) looked explicitly and systematically at the coverage of selected core issues in Fund surveillance, with a view to verifying the application of the "macroeconomic relevance test". More generally, these reviews assessed the way surveillance was evolving on account of the range of initiatives adopted to strengthen the international financial architecture.

The starting point of the two reviews was the recognition that the conduct of surveillance had evolved profoundly as a result of a continuous effort to adapt it to changes in the global environment. This adaptation process had affected all components of the framework of surveillance, namely its coverage, tools, and modalities.

Coverage had expanded to a wider range of issues, with FSS now integrally representing a core task of the Fund; new tools (notably FSAPs and ROSCs) had been developed to address these issues; and the modalities of surveillance had been adapted, with a view to make it more continuous and to enhance the integration between bilateral and multilateral exercises.

\section{Issues in the Coverage of Surveillance}

The reviews confirmed that the conduct of surveillance under its broadened framework had presented important implementation challenges for the Fund along three dimensions:

- the focus of surveillance;

- the quality and depth of its analysis; and 
- the integration of the framework's different components into an "overall coherent assessment" (IMF, 2002a, p. 15) of a country's situation.

The expanded range of issues identified as potentially relevant for surveillance had made it more difficult to maintain an appropriate focus for the exercise, i.e. covering the most critical issues of a country's economic and financial situation. However, the reviews found that the broadened framework of surveillance had helped draw attention to a range of "new" issues critical for its effectiveness, without losing focus. Moreover, this framework had been applied selectively. In fact, non-core structural and institutional issues had been addressed primarily in accordance with the macroeconomic relevance test, whereas macroeconomic developments and policies had remained the mainstay of surveillance activities in all countries.

In line with the notion that Fund surveillance is not a one-size-fits-all exercise, its focus had varied considerably across country groups, with much of the variation deemed to appropriately reflect differences in country-specific circumstances.

With particular reference to FSS, staff emphasized that, by that time, this activity had taken on a more comprehensive nature, since it had been extended to cover the banking sector, non-bank financial institutions, and organized financial markets. Coverage of financial sector issues was found to have deepened considerably, with a clear trend toward greater discussion of such issues as banking sector soundness and the adequacy of a country's prudential and supervisory frameworks. Furthermore, coverage of the linkages between the financial sector and other sectors was recognized as a key development since the Asian crisis.

However, the coverage of financial sector issues was found to show substantial variation (IMF, 2002b, p. 40). For example, this coverage was substantial for some advanced countries, but limited to description of recent initiatives for others. Importantly, this coverage was generally brief for euro area countries, except for those that had participated in the FSAP. For emerging market countries, coverage was deemed to be substantial, although with variable focus (IMF, 2002b, table 1, p. 33).

To be sure, it is worth noting that the unevenness in the coverage of financial sector issues was to some extent hardly surprising, and even desirable, as it could partly be attributed to differences in the intensity of concerns about the vulnerabilities of a country's financial sector. Such unevenness was thus just reflecting well-established guidelines mandating that coverage of financial sector issues should naturally vary according to country-specific circumstances, notably the potential interactions between macroeconomic and financial sector developments.

Overall, the 2000 and 2002 Surveillance Reviews were useful to increase the awareness that ensuring a proper focus of surveillance was only one ingredient for it to be effective: in fact, an equally important role had to be played by the ability to maintain satisfactory depth and quality of analysis.

Against this background, two main results of the reviews stood out.

First, while the coverage of financial sector issues had become "a standard element of Fund surveillance" (IMF, 2002a, p. 10), the reviews highlighted the important implications in terms of resources and expertise that derived from the broader framework of surveillance. In 
particular, limited information, expertise, or resources had indeed frequently constituted a constraint for an adequate, uniform, and in-depth treatment of the new areas of surveillance.

Secondly, a country's participation in the FSAP played a crucial role in accounting for the unevenness in the coverage of financial sector issues (IMF, 2002a, p. 12). The FSAP had proved itself as the tool capable of offering the most extensive coverage of the financial sector, as well as of than providing key diagnostics and recommendations. These findings were directly attributed to its explicit focus on the linkages between financial system developments and macroeconomic performance.

For countries that did not participate in the FSAP, a similar depth of coverage of financial sector issues could generally only be found in two cases:

- where a financial sector crisis had occurred, and thus considerable technical work had been done by the Fund, the World Bank, and other institutions; and

- where the existence of important financial sector weaknesses had been established for some years.

\section{Integrating the Elements of the Broader Framework of Surveillance}

One of the most relevant outcomes of the 2002 Surveillance Review was its explicit recognition of the operational consequences on the conduct of surveillance arising from the Fund's expanded agenda. In fact, the review proved itself remarkably predictive in stressing the importance of the third component, other than focus and depth, underpinning the effectiveness of surveillance, namely the proper integration of the "new" elements of the broadened framework for surveillance into the "traditional" coverage of macroeconomic and structural policies.

The review clearly underscored that the quality of surveillance ultimately depended on the ability to reach such integration: "covering the various elements of the broadened framework does not automatically amount to a well-integrated assessment of a country's macroeconomic conditions, vulnerabilities, and policy challenges. Proper integration of these elements would seem essential if the broadened framework is to strengthen surveillance" (IMF, 2002b, p. 44). In other terms, reaching this integration would be key to achieve a "unified and coherent overall assessment" of a country's macroeconomic situation, crisis vulnerabilities, and the resulting policy challenges.

Against this background, the review underlined that the integration between old and new core areas of surveillance had showed mixed results.

On the one hand, in several Article IV reports for emerging market economies, such as the countries affected by the Asian crisis, the various components of surveillance did add up to a unified, coherent overall assessment. In these cases, the discussions on external vulnerabilities, including those in the financial and corporate sectors, had served as the "point of entry" to the analysis of macroeconomic policies (as well as of structural and institutional reforms). More generally, a satisfactory integration of all elements of surveillance was acknowledged for those countries where the quality of coverage had been high for each single element of the broadened framework. 
On the other hand, however, the review recognized that, in many other countries, such integration had not been fully achieved yet. In particular, and in striking similarity to what the Crow Report had found three years earlier in a significant number of countries, coverage of financial sector issues was still largely considered as an "add-on to a well integrated macroeconomic analysis" (IMF 2002b, p. 44). The main factor to account for such a finding was deemed to be the inadequacy of the information available in the absence of FSAP participation (by the time of the review, FSAPs had been completed for only 14 percent of the Fund's membership).

Overall, the findings of the 2002 Review laid the groundwork for one of the most important lessons drawn by the Fund, namely that "the quality of Fund surveillance under the broadened framework will primarily depend on the quality of coverage of its elements. Strengthening the coverage of "new" elements will thus likely be critical for the overall effectiveness of surveillance" (IMF 2002b, p. 49).

This lesson stands out as it makes clear that the need to ensure an adequate coverage of financial sector issues was not only important in and of itself, but it was also crucial to the objective of reaching a "unified and coherent overall assessment" of a country's situation. In fact, an inadequate coverage of financial sector issues (as well as of other "new" issues in Fund surveillance) could carry "negative externalities", as it could prevent obtaining the targeted integration among all of the individual components of surveillance. Ultimately, it became even clearer that the effectiveness of surveillance would depend not only on the coverage of financial sector issues, but also on the ability to integrate these "new" issues with the traditional core areas of surveillance.

The 2002 Review had thus made it all the more evident that if FSS were to be treated as part of the core of the Fund's surveillance activities, the quality of treatment would have to measure up to the quality of coverage of other core areas, notably macroeconomic policies and exchange rate issues.

This important finding led the Board to agree on the need to bring the coverage of financial sector issues "up to par" with coverage of other core areas of surveillance. To this end, the 2002 Operational Guidance Note that followed the Review explicitly underscored that "the relevant benchmark for the quality of... [financial sector]...coverage should be that of other core areas" (IMF, 2002d).

The Note began identifying the elements that would help improve the coverage of financial sector issues, and emphasized that the focus would have to be on:

- the assessment of financial sector conditions;

- the linkages with macroeconomic developments and prospects; and

- $\quad$ the policy measures to address identified weaknesses.

However, two years later, the 2004 Surveillance Review, while acknowledging some improvements, recognized that, in many cases, financial sector coverage in Article IV reports "was not yet at par with coverage in other main areas" (IMF, 2004, p. 16), and had indeed varied substantially across countries.

In particular, coverage was generally broader for emerging market countries in which the discussions provided substantial insights on macro-financial linkages; besides, many reports, 
particularly for industrial countries, offered a focused and selective discussion of financial sector issues. However, for developing countries, coverage was uneven, varying "from a thorough coverage of the health of the financial sector to a virtual absence of any discussion" (IMF 2004, p. 17).

Against this background, in order to make further progress, the Board took the important step of setting out four "monitorable strategic priority objectives" that would function as a guide to staff for the next surveillance review. Enhancing FSS was one such priority objectives.

\section{Operational Consequences of the 2002 and 2004 Reviews}

The main results of the 2002 and 2004 Surveillance Reviews were particularly noteworthy as they more forcefully pointed out that the objective of bringing the coverage of financial sector issues up-to-par with that of other core areas of surveillance carried relevant resource and expertise implications. In particular, the unevenness in the coverage of financial sector issues was explicitly recognized as a reflection, inter alia, of "resources and expertise brought to bear on the analysis of these issues" (IMF, 2002b, p. 40).

As we have seen throughout the paper, the availability of adequate financial expertise had been recognized as a crucial precondition for the Fund's successful involvement in FSS ever since the expansion of the scope of surveillance in the aftermath of the Mexican crisis. Its importance had indeed been underscored by three special reviews conducted in the second half of the 1990s, namely the Whittome Report on Fund surveillance in Mexico in 1993-94, the March 1998 internal Review of Surveillance on the Asian crisis countries, and the Crow Report.

Moreover, in the March 1997 discussion on the framework for financial stability, the Board itself had acknowledged that it would take time for staff to develop the expertise and knowledge necessary to carry out an effective analysis of banking and financial sector issues.

Against this background, the 2000 and 2002 Surveillance Reviews made the Fund more aware that a comprehensive analysis of a member country's financial sector was "rarely achieved without the in-depth analysis afforded by prior participation in the FSAP... [and indeed was] ... generally not possible solely with the staff resources devoted to regular Article IV consultations" (IMF, 2002b, p. 47), particularly for non-bank financial institutions and organized financial markets.

Given the constraints on the number of FSAPs that could be concluded in a given year, the Fund engaged in devising alternative means to strengthen FSS in cases where: (i) a member had not participated in an FSAP; or (ii) "significant developments" had occurred since FSAP participation.

To this end, in April 2002 the Board approved a remedial measure consisting of reinforcing Article IV mission teams from area departments ${ }^{59}$ by deploying staff with financial sector

\footnotetext{
${ }^{59}$ Five "Area" departments are responsible, across macro-geographical regions, for Article IV consultations. Among "functional" departments, those most involved in the Fund's work on financial and capital market issues are the Research Department; the Monetary and Financial Markets Department; and the Strategy, Policy, and Review Department.
} 
expertise from such functional departments as Monetary and Exchange Affairs (renamed Monetary and Financial Systems Department - MFD since May 2003) or the International Capital Market - ICM ${ }^{60}$.

This measure has subsequently proved itself as the single most effective measure to improve the coverage of financial sector issues in bilateral surveillance. Both the 2004 Review (IMF, 2004) and the more recent 2008 Review of Surveillance (IMF, 2008c) have indeed acknowledged that enhanced quality and depth of coverage of financial sector issues were evident for those Article IV consultations that had benefited from substantial input from financial experts of functional departments. These consultations resulted in richer analyses of financial sector risks, vulnerabilities, and transmission channels, which underpinned more specific policy advice.

It is worth noting that the shortage of adequate technical expertise within surveillance teams carries potential negative consequences not only for the quality of the coverage of financial sector issues in Article IV consultations, but also for the usefulness of the FSAP as an input to such consultations.

This risk was well-emphasized by the Fund's Independent Evaluation Office (IEO) in its 2006 review of the FSAP. In fact, the availability of adequate technical expertise within surveillance teams was found to be "the major constraint on the effectiveness of follow-up work on FSAP recommendations when complex issues were involved" (IEO, 2006, p. 4). In particular, the IEO warned that in many cases where financial expertise was lacking, the process of tracking the implementation of FSAP recommendations was to some extent compromised, as this process had taken " $a$ 'checklist' approach of enumerating measures rather than appraising whether underlying vulnerabilities have been addressed" (IEO, 2006, p. 4).

The decision to deploy financial experts from functional departments within Article IV mission teams, and to allow these experts to train staff in area departments, was a further recognition of the important relationship between the quality of FSS and, inter alia, some aspects of the Fund's internal organization, notably the allocation of financial sector expertise among the Fund's departments.

Over the years, the Fund has taken various actions to ensure that the institution develop the necessary expertise to effectively carry out its expanded involvement in financial sector issues and keep pace with the globalization and sophistication of international finance. In this context, Management has even sought the advice of external experts regarding the effectiveness of the Fund's internal organization of the work on financial sector and capital markets ${ }^{61}$.

\footnotetext{
${ }^{60}$ It should be noted that financial experts from MAE had been associated with some Article IV missions as early as the second half of the 1990s, in countries requiring particular expertise in analyzing the conditions of the banking sector.

${ }^{61}$ Such external advice has generally led to follow-up studies carried out by internal task forces that, in turn, have given rise to major organizational changes with the setting-up of new departments and the merging of others. For example, in October 2000, the Managing Director Köhler announced the formation of a Financial Sector Review Group (IMF, 2000f) to provide the IMF with an independent perspective on how the Fund should organize its financial sector and capital markets work. Similarly, in June 2005 the Managing Director de
} 
More recently, on account of the Fund's tighter budget, financial sector expertise is intended to be used strategically, by following a "risk-based" approach, centered on the criteria of systemic or regional importance, relevance of vulnerabilities, and importance of financial development issues for macroeconomic or external stability (IMF, 2008c).

The initiatives undertaken to further improve FSS as a result of the lessons drawn from the global crisis, including the innovations introduced in the FSAP, have further highlighted the difficult tradeoffs in the allocation of the Fund's financial sector expertise in a constrained budget environment (IMF, 2009e, p. 22 and 2009f, p. 42).

\section{Financial Sector Surveillance in the Aftermath of the global CRisis}

The importance of further strengthening the Fund's analysis of the financial sector was reiterated in the Strategic Review, launched in mid-2004, and in the subsequent MediumTerm Strategy unveiled in September 2005 (IMF, 2005e and 2006).

Further attention was devoted to two long-standing and interconnected issues that set the stage for the current discussion on how to further improve FSS: the need for effectively following-up on the FSAP findings and recommendations in the context of Article IV consultations; and the fuller integration of financial sector issues into the Fund's traditional macroeconomic framework of surveillance.

The global financial turmoil that broke out in August 2007 has shown, inter alia, that these issues are yet to be fully addressed. They thus represent the priorities of the Fund's ongoing work on bilateral FSS and the analysis of macro-financial linkages, which is being informed by the lessons drawn from the crisis.

\section{A. Integrating Financial Sector Issues into Macroeconomic Surveillance: the 2007 Financial Sector Task Force}

New important initiatives to improve the coverage of financial sector issues and their integration into Article IV consultations were adopted to follow-up on the recommendations by the Review Group set up by the Managing Director in June 2005 (IMF, 2005b). The ensuing "McDonough Report" acknowledged the advances made by the Fund in integrating financial and capital market issues into its traditional macro activities, but also noted that several components of the effort remained a work in progress ${ }^{62}$.

\footnotetext{
Rato established the Working Group to review the Fund's financial sector work (IMF, 2005b). The new Monetary and Capital Markets Department established in August 2006 by merging MFD and ICM, received a clear and strong mandate to support area departments in conducting FSS at the country level. See Bossone (2008, pp. 18-20) for a concise review of such external and internal reports and the ensuing changes in the Fund's organization.

${ }^{62}$ In the same vein, a former Director of the IMF's Policy Development and Review Department has recently noticed that "despite recent efforts, there remains a need for a genuine integration of financial sector issues with the world class macro economic analysis that has been the hallmark of the Fund over its entire history" (Boorman, 2007).
} 
The most significant of such initiatives was the establishment of a Financial Sector Task Force, explicitly directed at developing a "broad organizing framework" to facilitate the integration of financial sector issues into the macroeconomic analysis.

It should be noted that Fund staff had already outlined the main features of a framework for financial stability analysis on the occasion of the review of the Financial Soundness Indicators in May $2003^{63}$.

The underlying idea was that a better integration of the different dimensions of FSS would be instrumental in more effectively assessing the impact of shocks to the financial system.

In staff's view (IMF, 2003c), this objective should involve three phases:

- the identification of the risk of a shock hitting the financial sector;

- the assessment of the vulnerability of the financial sector to these shocks and their potential impact on capital adequacy; and

- the analysis of macro-financial linkages to obtain an indication of the effect on macroeconomic conditions and debt sustainability, if the intermediation capacity of the financial sector were impaired.

The features of this framework were subsequently expanded by building on the experience developed in the context of the FSAP, and were elaborated in the joint IMF-World Bank Handbook on Financial Sector Assessment, published in September 2005 (IMF, 2005d).

The Handbook presented an overall analytical framework, consisting of a wide range of tools and techniques ${ }^{64}$, whose primary objective is to achieve an integrated analysis of two topical issues: the stability and the development of the financial system ${ }^{65}$.

Against this background, the work of the Financial Sector Task Force set itself apart in underscoring that a closer integration of financial sector analysis into the macroeconomic template that supports Article IV surveillance ${ }^{66}$ is not only a matter of content (i.e., better analytical tools), but also of more effective internal processes.

\footnotetext{
${ }^{63}$ The Board had explicitly welcomed such framework as "a useful tool for integrating macro-prudential surveillance, analysis of macro-financial linkages, and surveillance of macroeconomic conditions" (IMF, 2003, p. 2).

${ }^{64}$ Including: 1) macroprudential analysis, made up of the following basic components: stress testing, scenario analysis, FSIs, balance sheet analysis, and macro-financial linkages; 2) analysis of financial sector structure, focusing on such aspects as efficiency, competitiveness, concentration, liquidity, and access; 3) assessment of observance and implementation of relevant international standards, codes, and best practices in the financial sector; and 4) analysis of country-specific stability and development issues.

${ }^{65}$ The simultaneous attention to these two broad issues was recognition that financial stability considerations and financial sector development policies were intrinsically interlinked. In fact, effective surveillance of national financial systems had to be accompanied by a harmonization and international convergence of key components of financial policies in order to help minimize the risks of cross-border spillovers of financial system disturbances.

${ }^{66}$ The 2006 FSAP review by the IEO pointed out that “...progress in establishing a framework to enhance financial sector surveillance outside of the FSAP has been limited. Draft guidelines on financial sector surveillance were initially prepared over a year ago but have not been finalized because of area department concerns that they called for more than departments could deliver with existing resources. Consequently, the
} 
On content, the task force's main contribution was the setting forth of four issues that should be addressed in Article IV surveillance (IMF, 2008d, p. 55):

- the channels of interaction between the macroeconomy and financial markets, i.e. macro-financial linkages;

- the role of the financial sector in initiating, amplifying, or muting disturbances to a country's economic system, and the possibility of potential spillovers from systemically important countries to the global economy;

- the role of the financial sector in facilitating or retarding growth; and

- a risk assessment of the potential for a financial crisis.

One of the most significant recommendations of the Task Force was a more systematic approach to prioritizing financial sector work in Article IV consultations. As far as the FSAP was concerned, the Task Force underscored that in order to facilitate its integration into Article IVs the exercise should strive to emphasize the macro-relevance nature of their findings, and should prioritize their recommendations.

The circulation in April 2009 of an internal FSS Guidance Note (IMF, 2009e, Box 1, p. 7) marked an important progress toward making operational the organizing framework for bilateral FSS called for by the 2007 Task Force.

With a view to assess both the likelihood and impact of risks to financial stability, the Note provides specific guidance on how to assess possible sources of risks, describes qualitative and quantitative diagnostic tools to assess various types of risks, and points out possible policy recommendations depending on country circumstances.

On the ways to improve the internal process, the task force emphasized that FSS should be " $a$ continuous process" for systemically or regionally important countries, and for countries at risk. To this end, it was emphasized that cooperation and exchange of information among Fund's departments should play a relevant role.

In this regard, the recently-announced establishment of an interdepartmental Financial Surveillance Group (IMF, 2009e, p. 14) is a further recognition of the importance of interdepartmental cooperation, notably to bridge the various vehicles for surveillance and integrate multilateral and cross-country risk analyses into the bilateral surveillance carried out by area departments.

\section{B. The 2008 Triennial Surveillance Review}

In October 2008, the Triennial Surveillance Review (TSR) provided the Fund with a timely opportunity for discussing the state of surveillance in the face of the most severe financial crisis since the Great Depression (IMF, 2008c and 2008d). Specific attention was also paid to monitoring the progress toward meeting the four priority objectives set out by the 2004 Surveillance Review.

strategic guidance on the scope and objectives of enhancing this component of surveillance remain unclear" (IEO, 2006, Box 5.1, p. 30). 
To this end, the TSR carried out a thorough assessment of bilateral surveillance at the outbreak (August 2007) of what would develop into the global financial crisis. Four countries (the U.S., the U.K., Switzerland, and Germany) were used as case studies to evaluate the ability of surveillance to identify risks and vulnerabilities.

Such an assessment pointed out that bilateral surveillance had been successful in identifying most vulnerabilities and risks that had subsequently contributed to the above crisis, along with potential spillover channels. Many institutional aspects had also been correctly diagnosed.

However, it was recognized that surveillance made some "wrong calls", and did not make out the aggregate implications of the individually-identified risks. Perhaps more importantly, the Fund, together with most observers, had underestimated or not assessed quantitatively the scale and impact of such risks materializing, and this had hindered the ability to call for remedial policy actions.

These outcomes owed in part to the fact that surveillance had overlooked some specific factors, deemed as "known unknowns", such as the lack of information on exposures to mortgage-related assets and the complexity of some of these securities. Communication was also at fault, as surveillance had tended to obscure the degree of concerns about the identified risks through reassuring headline messages. Finally, the interbank money market freeze, perhaps the hallmark of the financial crisis, was missed as it came as an "unthinkable" surprise (IMF, 2008d, p. 80).

In order to develop remedial measures, the 2008 TSR elaborated on the practical conduct of FSS, which could be structured into four components: diagnosis of financial sector vulnerabilities; identification of macro-financial linkages; analysis of cross-border risk transmission; and provisions of financial sector policy advice (IMF, 2008d, pp. 41-47).

A crucial point was the clear recognition that the biggest challenges facing surveillance related to the analysis and identification of macro-financial linkages. In fact, both the review of staff reports, and surveys with stakeholders and mission chiefs had confirmed that "surveillance is significantly better at assessing financial sector vulnerabilities than at analyzing real-financial risk transmission channels" (IMF, 2008d, p. 42). In particular, it was the assessment of the impact of financial sector events on the real economy that was singled out as the most important test for the Fund.

In this regard, it is important to note that the analysis and identification of macro-financial linkages pose relevant conceptual and empirical challenges, as, for example, many of these linkages can operate in both directions. As a result, designing a uniform framework to monitor and assess these linkages has proven a complex task ${ }^{67}$. The TSR itself acknowledged that the lack of a satisfactory theoretical model and insufficient empirical work had both contributed to make the analysis of macro-financial linkages even more difficult.

One of the main outcomes of the 2008 TSR is that FSS and macro-financial linkages were included among the four areas deserving priority attention by surveillance in the period ahead

\footnotetext{
${ }^{67}$ To explicitly address these difficulties, in the spring of 2009 a Macro-Financial Unit was set up within the IMF Research Department (IMF, 2008b).
} 
(along with risk assessment, multilateral perspective, and analysis of exchange rates and external stability risks). These areas have thus been included as operational priorities in the first Statement on Surveillance Priorities (SSP), adopted by the Board in October 2008 and revised in September $2009^{68}$. The SSP is designed to help the Fund deliver on its mandate to promote international monetary and financial stability, and to lay a clear basis for monitoring and accountability ${ }^{69}$.

\section{The FSAP After Ten Years}

The FSAP is by now the Fund's key instrument for in-depth surveillance of a country's financial sector ${ }^{70}$.

Following its inception a decade ago, successive reviews of the FSAP have underscored that the exercise has significantly enhanced the Fund's comprehension of financial sector issues and risks that are essential to surveillance.

Within the Fund, area departments acknowledge that FSAP findings and recommendations have raised the coverage and quality of financial sector analysis in Article IV consultations, other than providing useful input into the discussions with national authorities.

National authorities in high-income countries have signaled that a major benefit of the FSAP is that "it offers an independent check-up of the health of the financial system, its infrastructure, and regulatory framework from an international perspective" (IMF, 2005a, p. 4). In low- and medium-income countries, the authorities see the FSAP also as "a tool that helps identify gaps and issues that need to be addressed to develop a more diversified, competitive, and inclusive financial sector" $"$.

In its 2006 review, the Fund's Independent Evaluation Office (IEO) judged the voluntary exercise as " $a$ distinct improvement in the IMF's ability to conduct financial sector surveillance and in understanding the important interlinkages between financial sector vulnerabilities and macroeconomic stability" (IEO, 2006, p. 1) $)^{72}$.

Against this background, the discussion sparked by the global financial crisis on the lessons for Fund surveillance has inevitably involved the FSAP as well. Recognizing that the FSAP

\footnotetext{
${ }^{68}$ See: IMF Executive Board Adopts Surveillance Priorities for 2008-2011. Press Release No. 08/238 (October 8, 2008). Available at: http://www.imf.org/external/np/sec/pr/2008/pr08238.htm. IMF Executive Board Revises Surveillance Priorities for 2008-2011. Press Release No. 09/336 (September 29, 2009). Available at: http://www.imf.org/external/np/sec/pr/2009/pr09336.htm

${ }^{69}$ Lavigne and Schembri (2009) assess the potential impact of the SSP, as well as of the 2007 Surveillance Decision.

${ }^{70}$ As of end-July 2009, the total number of completed, ongoing, or formally requested FSAP initial assessments reached 141, corresponding to 80 percent of the Fund's membership (IMF, 2009f). Among the G-20 countries that have not yet undertaken the exercise, China, Indonesia, and the U.S. are scheduled to do so in 2010.

${ }^{71}$ Most recently, respondents to a survey of country authorities, conducted as part of the 2009 Review, indicated that FSAPs have led to "clear gains in the depth of surveillance of financial sector issues" (IMF, 2009g, p. 42).

${ }^{72}$ See also the last review of the FSAP (IMF, 2009f).
} 
should continue to be a key element of the strategy for integrating financial sector work into Fund surveillance, the October 2008 IMFC Communiqué (IMF, 2008f) called for " $a$ reshaped FSAP that is more flexible, better integrated with the Fund's core surveillance mandate, and embraces regional perspectives". The commitment of all G-20 members, at the November 2008 Summit, to undertake an FSAP report provided further stimulus to review the program ${ }^{73}$.

A reassessment of the scope and modalities of the exercise was first necessary in order to overcome some known shortcomings. In fact, despite past efforts to streamline the exercise and better tailor its assessments to country circumstances, the key characteristics of the FSAP represent its limitations as a surveillance instrument: on the one hand, its voluntary nature constrains the scope for prioritization; on the other hand, the requirement that assessments be relatively comprehensive, coupled with tighter resource constraints at the Fund, accounts for the low frequency of FSAP missions.

Furthermore, some dynamics of the global crisis have made it clear that the FSAP needs to be adapted to a more complex financial environment than the one in which the program was framed. Perhaps more important, it is imperative for the FSAP to properly reflect the relevant lessons drawn from the financial crisis, which point to an expanded coverage of such issues as cross-border aspects of financial markets spillovers, assessment of macroprudential risks, and the financial sector's supervisory and regulatory framework ${ }^{74}$.

\section{Reshaping the FSAP}

In September 2009, the Executive Board reviewed the FSAP after ten years since its inception (IMF, 2009f). The review is a significant part of the Fund's strategy to strengthen its macro-financial surveillance, and has been informed, inter alia, by the objectives of improving the continuity of surveillance and the frequency and focus of FSAP assessments.

The starting point was the recognition that "the long time gap between FSAP updates is a major handicap for the analysis of financial sector vulnerabilities and macro-financial linkages" (IMF 2009f, p. 22).

The Board thus endorsed some major changes to the program, most notably the introduction of optional "modular" FSAP updates intended to help "fill the gap" between the two ends of the spectrum of bilateral FSS: standard Article IV consultations and full-fledged FSAP assessments.

This option allows the Fund and the Bank to launch, respectively, stand-alone "stability" and "developmental" assessment modules that provide distinct, albeit complementary perspectives on a country's financial sector. Importantly, a major objective of the modular

\footnotetext{
${ }^{73}$ Moreover, another recognition of the importance of the program has come from the decision to use evidence from FSAP reports as input to the periodic "peer reviews" agreed upon by the members of the Financial Stability Board (Group of Twenty, 2009).

${ }^{74}$ In this regard, a background paper for the 2009 FSAP review (IMF, 2009g) underscores that, in retrospect, such issues as liquidity risks, crisis preparedness, bank resolution and external funding risks should have been given greater emphasis in FSAP assessments, regardless of the level of sophistication of the financial system.
} 
option is to "eliminate the rigidity inherent in the current "one-size-update-fits-all" approach and allow... [the Fund and the Bank ]... to respond more flexibly to country circumstances... [and]...priorities" (IMF, 2009f, p. 32).

As a further measure toward a more continuous and effective surveillance, the Board also agreed to complement the FSAP by an enhanced off-site monitoring by staff and more regular contacts with country authorities, building on the parallel effort of strengthening the financial analysis capabilities in area departments.

Finally, the analytical toolkit of the program was strengthened through further refinements of methodologies such as macro stress-testing ${ }^{75}$, balance sheets analysis, and market-based risk indicators, as well as through the development of tools in new areas highlighted by the crisis, notably the assessment of macroprudential risks.

In order to make the stability assessments more candid, transparent and comparable, the review introduced a standardized "Risk Assessment Matrix" ", which helps identify for each country: i) the nature or source of the main threats to financial sector stability; ii) the likelihood of a severe realization of such threats over a 3 -year time horizon, and; iii) the expected impact on financial stability if the threats materialize.

Against the backdrop of the several initiatives aimed at strengthening the crisis prevention capabilities of the FSAP and, more generally, of the Fund's FSS, it is imperative to emphasize once again that the issuance of warnings on a country's risks and vulnerabilities is a necessary but not sufficient condition for the effectiveness of Fund surveillance.

The 2009 Review itself included a further recognition of this limitation, by making it clear that "the FSAP's focus on identifying underlying vulnerabilities could not, by itself, address them. Identification of vulnerabilities could only lead to a solution if the country authorities decided to implement the recommendations of the FSAP" (IMF, 2009f, p.18).

\section{Integrating FSAP Assessments into Article IV Surveillance}

It is most noticeable that some of the changes in the FSAP introduced by the 2009 Review, including the modular option, have been explicitly targeted to ensure a closer integration of the program's findings into Article IV reports. As noted throughout the paper, this is a longstanding issue, and a brief recollection is thus warranted.

\footnotetext{
75 The 2009 FSAP Review underscored that the recent financial crisis had prompted a critical re-assessment of stress testing tools and methodologies, as some of the stress tests performed in the run-up to the crisis missed important sources of instability. An internal Fund evaluation of how stress tests performed during the crisis (IMF, 2009f) has proposed a number of improvements in the stress testing methodologies based on this experience. This evaluation stressed that "chief among... [these improvements]... will be efforts to obtain adequate data for the tests, covering both on-and off-balance sheet exposures-which requires the full cooperation of the authorities" (IMF, 2009f, p. 35). See IMF (2009b and 2009c) for more general discussions on the information gaps and statistical needs evidenced by the crisis.

${ }^{76}$ See IMF (2009f, Appendix IV).
} 
The importance of using bilateral surveillance to follow-up, in the context of a full macroeconomic analysis, on the issues revealed by the FSAP had already been pointed out at the inception of the program. In fact, given the complementarities between the two vehicles, it was immediately apparent that the success of the FSAP would depend on an effective exploitation of the synergies with the Article IV consultation process.

Fund staff understood that while the FSAP would provide a framework for a comprehensive, in-depth assessment of a country's financial sector, the exercise had limitations as a surveillance instrument, in that it is voluntary in nature and low in frequency (updates now take place every 6 years on average). There was thus awareness that, given its characteristics and internal resource constraints, the FSAP could not be the only tool for monitoring the financial sector, but it had to be complemented by additional surveillance tools to make this monitoring more continuous and effective.

As a result, it was apparent that Article IV consultations would have to function as the "primary instrument" (IMF, 2004, p. 16) of systematic and ongoing bilateral FSS, on account of their mandatory nature and high frequency, taking place usually on an annual basis. However, Article IV consultations displayed their own shortcoming, in that their coverage of financial sector issues is necessarily more limited than the FSAP, as these issues are dealt with only if they are relevant for external stability.

This consequential trade-off made it all the more clear that a closer integration of the FSAP findings and recommendations into the Article IV consultation process was essential in order to deliver on the original objective of making the FSAP "the preferred vehicle for conducting financial sector assessments as input to Fund surveillance” (IMF, 2000h).

The importance of ensuring such integration was effectively illustrated by the Fund's IEO in its 2006 review of the program. Strengthening the links between the FSAP and Fund surveillance was needed not only to assess a country's overall macro-financial stability and potential vulnerabilities, but also to formulate "policy recommendations that are set in a coherent framework combining macroeconomic and financial sector analysis" (IEO, 2006, p. 41).

This integration has not been fully achieved yet, notwithstanding the considerable efforts exerted by the Fund. In its review, the IEO considered the FSAP to be at a critical crossroads, and indicated that 'financial stability assessments have not yet been fully 'mainstreamed' as a regular part of IMF surveillance" (IEO, 2006, p. 1).

Importantly, the IEO underscored that this lack of integration could not only diminish the effectiveness of the FSAP exercise, but also carry negative consequences for the overall quality of FSS. In fact, given that Article IV reports constitute the focus of Board discussions, "failure to adequately integrate FSAP results into those reports has tended to lower the prominence of financial sector issues, even when the FSSA did spell out the issues" (IEO, 2006, p. 27).

The IEO evaluation was also noteworthy for having assessed a crucial determinant of the impact of the FSAP, namely the extent of the follow-up work. The main finding was that the quality of the FSAP proved to be crucial in determining the intensity of the follow-up work in ensuing Article IV consultations: in fact, effective follow-ups had proved to be more 
difficult in cases where the FSAP lacked a clear sense of priorities among the different measures proposed in strengthening a country's financial sector (IEO, 2006, p. 28).

The global financial crisis has provided additional reasons to further advance the integration of FSAP findings into Article IV consultations. In this regard, the new Risk Assessment Matrix that will be produced in the context of the FSAP is specifically meant to be used as a basis for discussing financial stability issues in Article IV consultations.

More broadly, the crisis has also clearly shown that more complex and increasingly interconnected global financial landscapes demand that the FSAP first adapt its assessments in a crucial respect, namely the need to take on a deeper cross-border perspective. In fact, currently the FSAP "does not assess vulnerabilities associated with problems abroad.... and ...vulnerabilities associated with a global crisis" (IMF, 2009g, p. 23).

In particular, FSAPs need to focus more squarely on cross-border financial linkages that propagate and amplify the transmission of financial shocks (IMF, 2009f, p. 37).

As a necessary complement to this adaptation effort, FSAP assessments have to be more systematically informed by the vehicles of the Fund's multilateral surveillance, including the new Early Warning Exercise (EWE) conducted jointly with the Financial Stability Board ${ }^{77}$ (IMF, 20091).

The EWE aims to identify systemic "tail" risks, i.e., low probability-high impact risks to the global outlook, by using a broad array of quantitative and qualitative tools and techniques, as well as market information. Moreover, the exercise tries to assess the impact of such risks and vulnerabilities with a view to promote coordinated remedial actions, and evaluates the possible consequences of policy inactions.

As a joint product of the enhanced cooperation between the Fund and the FSB ${ }^{78}$, a distinctive strength of the exercise is that it provides an integrated perspective on risks and vulnerabilities by effectively combining the Fund's economic and macro-financial analysis with the FSB's specialization on financial system regulatory and supervisory issues.

\footnotetext{
77 At the April 2009 G-20 Leaders Summit in London, the Financial Stability Forum was re-established as the Financial Stability Board (FSB) with a broadened mandate to promote financial stability, expanded membership, stronger institutional basis and enhanced capacity. At their September 2009 Pittsburgh Summit, the G20 Leaders endorsed the Charter that formally establishes the FSB to coordinate at the international level the work of national financial authorities and international standard setting bodies in order to develop and promote the implementation of effective regulatory, supervisory and other financial sector policies. As part of its mandate, the FSB will: assess vulnerabilities affecting the global financial system; identify and review the regulatory, supervisory and related actions needed to address such vulnerabilities; promote coordination and information exchange among authorities responsible for financial stability; monitor and advise on market developments and their implications for regulatory policy; set guidelines for and support the establishment of supervisory colleges; support contingency planning for cross-border crisis management, particularly with respect to systemically important firms. Moreover, in collaboration with the international financial institutions, the FSB will address vulnerabilities affecting financial systems in the interest of global financial stability. See: http://www.financialstabilityboard.org

78 Joint Letter by the Managing Director and the Chairman of the FSB issued ahead of the G-20 Leaders' Summit on Financial Markets and the World Economy in Washington, D.C. (November 13, 2008). Available at: http://www.financialstabilityboard.org/list/fsb_publications/tid_78/index.htm
} 
Crucially, the early warning exercise is meant to be an integral part of Fund surveillance, along many dimensions. First, the findings of the Fund's key vehicles of multilateral surveillance, the World Economic Outlook (WEO) and Global Financial Stability Report (GFSR) are critical inputs to the EWE. Furthermore, the exercise is intended to complement these vehicles, as its findings contribute to the discussion of tail risks in surveillance, and these risks would result in policy recommendations different from those generated by the baseline scenarios presented in the WEO and the GFSR. Finally, the Fund's multilateral and bilateral surveillance is the mechanism to follow up on the EWE's warnings and policy recommendations (IMF, 20091). 


\section{CONCLUding ReMARKS}

Less than two years ago it was not infrequent to hear distinguished economists, opinion makers, and politicians asking whether the huge expansion of private capital markets and the absence of major sovereign crises would greatly diminish the relevance and role of the Fund.

Recent events have provided a clear answer to this question. As in previous crisis episodes, the Fund is playing the role of "firefighter", while the international financial community is involved in an intense debate on how to strengthen the international financial architecture and enhance crisis prevention.

Surveillance is the mainstay of the Fund's crisis prevention activities. The Fund's ability to effectively cover financial sector issues, and to ensure that its findings are fully integrated into the macroeconomic analysis, is critical to the quality, credibility, and impact of the institution's policy advice to member countries.

The actual conduct of Fund surveillance almost by definition develops in parallel with the evolution of financial markets: smooth and tranquil periods are occasionally, and often abruptly, shaken by unexpected financial turbulences that reveal previously unknown (or underestimated) sources of risks and vulnerabilities. These usually lead to reconsider wellestablished views on how financial markets function and the role of market discipline, and to update regulatory and supervisory practices.

Following the Mexican and Asian crises, where financial factors played a major role, and in response to the calls from the international financial community, the Fund began undertaking a major effort to deepen its involvement in Financial Sector Surveillance (FSS). The explicit objective was to improve crisis prevention, notably by better understanding the so-called "macro-financial linkages", the two-way transmission channels between the stability of financial markets and a country's macroeconomic performance.

This paper analyzed comprehensively, and put into a historical perspective, the expansion of the scope of surveillance beyond the traditional macroeconomic areas, as well as the evolution of such process in the face of major financial events.

The Fund's involvement in FSS can be broadly broken down into a preliminary stage and two main phases.

The preliminary stage, dating back to the 1980 s and early 1990 s, was mainly related to the process of monetary and financial deregulation embraced by several countries, a process that was marked by financial crises affecting over two-thirds of the Fund's membership. In those years, the Fund's coverage of financial sector issues had not so much to do with surveillance, but rather with the institution's research and technical assistance activities.

This preliminary stage was characterized by an increasing awareness that financial liberalization is generally followed by rapid credit growth and excessive risk-taking if reforms are not tempered by appropriate prudential supervision and regulation. The main lesson learned by the Fund, and by the international community at large, was that financial deregulation needs to be carefully sequenced and supported by appropriate regulatory frameworks and solid market infrastructures.

The first "official" phase of FSS spans from the Mexican crisis (1994-95) to the Asian crises (1997-98) and the crises of the late-1990s (Russia and Brazil). All these events showed in the 
most dramatic way the unintended consequences of financial globalization, characterized by swift increases in risk aversion, sudden stops or capital reversals, and episodes of "pure" contagion, i.e., the involvement of seemingly unrelated and often sound countries.

The main characteristic of this first phase was the expansion of the scope of Fund surveillance to include financial sector issues among its core areas. This important step took place in parallel with the work done by the institution to follow up on the calls from the international community to improve several aspects of the global financial architecture, such as transparency, data provision, and the adoption of international standards and codes. Given the Fund's unique position as a universal institution and its comparative advantages, surveillance became the vehicle used to engage its membership in the reform process to strengthen the stability of financial systems, culminated in 1999 with the launch of the Financial Sector Assessment Program (FSAP), jointly administered with the World Bank.

The second phase of the Fund's involvement in FSS relates to the efforts made to bring the coverage of financial sector issues "up to par" with the coverage of other "traditional" core areas of surveillance. This phase more clearly highlighted the resource implications of FSS, and was characterized by two main interrelated objectives: improving the coverage of financial sector issues in Article IV consultations, and strengthening the links between FSAP findings and the Article IV process.

As a result of the expansion of the scope of Fund surveillance, financial sector issues are now considered among the core areas of surveillance, along with the more traditional monetary, fiscal, and exchange rate policies.

This expansion has often forced Fund staff to rethink a well-established macroeconomic analytical framework, and to extend it toward somewhat less familiar territories; these involve issues such as financial stability, the appropriateness of a country's regulatory and supervisory structure, and a more systematic analysis of macro-financial linkages, including their potential for cross-country spillovers.

Fund staff has scored an array of successes in developing such an analytical framework, as well as in enriching it over the years with a wide range of tools and techniques to support FSS.

However, the recent crisis, with its origin in some of the largest and most sophisticated financial markets in the world, its almost unprecedented size and global nature, has demonstrated that despite the long-standing emphasis on the analysis of macro-financial linkages and the advancement made by the institution toward monitoring the stability of the international financial system, the Fund's framework for macro-financial surveillance needs to be further improved.

While many risks and vulnerabilities were identified, often repeatedly, Fund surveillance in the run-up to the global crisis has fallen short of meeting the expectations of the institution's stakeholders; discussions are taking place to understand what prevented surveillance from being fully effective in its crisis prevention role.

Overall, although information gaps, including on what has come to be known as the "shadow banking system", seriously undermined the Fund's assessment capacity, a consensus is emerging that the warnings provided before the crisis by official bodies, including the Fund, 
were generally insufficiently specific to attract the attention of policy makers and, more importantly, to induce them to act (IMF, 2009a, p. 2).

This outcome may owe in part to some features of the Fund's governance structure, as well as to the challenging task of clearly communicating to the public the Fund's assessments of financial risks and vulnerabilities without undermining confidence and triggering adverse market reactions. Moreover, the Fund inherently faces a delicate balancing act between its dual role as both confidential advisor to country authorities and public overseer on economic and financial risks ${ }^{79}$.

Against this background, it seems difficult at first glance to escape a sense of déjà vu with regard to the long-standing process of Fund's involvement in FSS.

As we have seen throughout the paper, macro-financial linkages have been the object of the Fund's analysis as early as the beginning of the 1990s. The FSAP was put in place in 1999 with the explicit goal of bringing the linkages between financial sector soundness and macroeconomic developments to the core of Fund surveillance. The various reviews of the program soon underscored the need for better integrating the FSAP into the Article IV process in order to ensure that bilateral surveillance follows up on the program's recommendations.

And yet the 2008 Triennial Surveillance Review has once again included among the areas deserving the highest priority in the period ahead a more rigorous analysis of macro-financial linkages, and a better integration of financial sector surveillance into macroeconomic analysis, including by leveraging FSAP findings in Article IV reports.

Ever since the expansion of the scope of Fund surveillance, in the aftermath of the Mexican crisis, to cover financial sector issues, successive reviews have emphasized both the progresses made in this area and the scope for further improvements. These reviews addressed several recurring themes, with the Board endorsing more focused analyses, more candid assessments by staff of a country's risks and vulnerabilities, a better integration of financial sector analysis, including FSAP recommendations, into the Article IV consultation process, and stronger cooperation with other international bodies.

The recurrence of these themes was also noted outside the Fund. One of the main findings of the external evaluation of surveillance (the Crow Report), released back in 1999, was that "improving financial sector surveillance was identified as an important task as long ago as 1995, and the pace of improvement has been slow" (IMF, 1999c, p. 67).

Against this background, we believe that our paper helps reconcile the above-mentioned sense of déjà $v u$ with the significant progresses made by the Fund since the Mexican crisis in covering financial sector issues. Our comprehensive analysis of the various steps taken by the Fund toward this goal demonstrates that this impression captures, to a large extent, only the appearance of things. More fundamentally, this impression overlooks the fact that the expansion of the scope of Fund surveillance to cover financial sector issues has made it an

\footnotetext{
${ }^{79}$ According to the Fund's transparency policy, country authorities retain the right to delete from reports, before publication, information deemed as "market sensitive".
} 
even more complex process, one that poses various types of challenges for the actual conduct of surveillance and its effectiveness.

As shown in the paper, in the face of a string of initiatives taken by the international community to strengthen the international financial architecture in the aftermath of the Mexican and Asian crises, Fund surveillance took on the crucial function of providing the mechanism through which the results of many of the above initiatives would "come together ... and filter" into the Fund's assessments of individual countries and, more generally, of the global economy (IMF, 2000a).

In this context, we believe it is fair to compare the Fund's efforts of improving FSS to a process of targeting an upward-moving object ${ }^{80}$. In fact, the expansion of the scope of Fund surveillance has taken place against the background of an increasingly complex global financial landscape, continued financial innovations, and rapid expansion in cross-border capital flows. These developments have all raised the frontier of FSS.

This has not only required new practices, tools, and expertise to cover issues outside of the Fund's traditional focus on macroeconomics, but has also created a need for effectively integrating the various components of surveillance into a consistent and unified summary assessment of a country's economic and financial situation. Staff soon became aware that the expansion of the Fund's coverage of financial sector issues would add a new dimension to surveillance, namely the need to integrate financial analysis into the macroeconomic framework used for Article IV consultations.

This integration has proved to be a major challenge to the efforts of advancing the effectiveness of surveillance, one that has been made more difficult by some characteristics and procedural mechanisms inherent in a complex institution. In this regard, one needs to clearly underscore that the objective of improving FSS is all but just introducing new tools and techniques, as one should not underestimate the necessary institutional, organizational and cultural changes that must complement the above goal, as well as its relevant resource implications. Moreover, FSS suffers from the lack of agreement on a unified theoretical model and analytical framework on how to integrate financial and macroeconomic analyses.

All in all, our study shows that while the recurrence of some surveillance themes may give the impression of a somewhat faltering process, the Fund's operations and policies are actually in a process of "continuous reform", much like the Fund's Executive Board is in a "continuous session". We are thus sympathetic to the view that the quest for making the Fund a center of excellence in financial sector analysis is "more as a marathon than a sprint" (McDonough Report, IMF 2005b).

The global crisis, and the ensuing international response to reform many components of the global financial system, is most likely marking the start of a new phase of Fund's involvement in FSS, for a number of reasons.

\footnotetext{
80 "And in other cases, like financial sector surveillance, the goalposts are constantly moving: as the world we analyze is becoming more complex, so is its analysis". As a result, it should not come as a surprise if "future surveillance reviews...[will] ....note both that progress was made and that more efforts are needed" (IMF 2008c, p. 11).
} 
First, the crisis has made policy makers more aware of old and new forms of systemic risks posed by a build up of financial vulnerabilities, and this has resulted in increased political support for initiatives aimed at safeguarding the stability of financial markets. The G-20 Leaders' commitment to undertake an FSAP assessment is a major example in this regard. In the same vein, the members of the Financial Stability Board, in committing themselves to pursue the maintenance of financial stability, agreed to undergo periodic "peer reviews" (Group of Twenty, 2009a).

Secondly, the role played by financial markets and products in triggering a global recession calls for deeper analyses of the adverse dynamics potentially triggered by such markets and products, as well as of their repercussions to the real economy. Macro-financial linkages have thus been placed even more to the center of Fund surveillance, signaling both the need for further expanding the scope of FSS, and the crucial importance of deepening its multilateral perspective, most notably to take into account the developments in global markets and the risks of cross-border spillovers.

Thirdly, the peculiar dynamics of the turmoil and its systemic nature call for the development of crisis prevention instruments that complement and integrate the Fund's macro-prudential analysis with a regulatory and supervisory perspective on risks and vulnerabilities in the financial system. International cooperation is once again crucial to this end. Following up on the calls from the G-20 Leaders and the IMFC, the Fund has started conducting early warning exercises in cooperation with the Financial Stability Board.

These exercises may address, inter alia, one of the most relevant lessons drawn from the global crisis, namely that identifying potential risks and vulnerabilities is a necessary but not sufficient condition for surveillance to be effective. In fact, warnings should be issued with appropriate specificity and candor, avoiding overly hedged language, for them to gain traction with national authorities. Early warning exercises can thus contribute to improve Fund surveillance by helping deliver warnings in the form of "effective, actionable messages" and policy recommendations that are conducive to the timely adoption of remedial measures by country authorities. Fund surveillance will be the mechanism to follow up on these warnings and policy recommendations; in turn, the findings of surveillance will be an input into the above exercises.

Overall, the Fund, together with other international organizations, is being a key player in shaping the official sector's response to the global turmoil, including the design of exit strategies. Similar to past episodes, surveillance is set to be the vehicle to disseminate to Fund members the lessons drawn from the crisis and help foster the adoption of corrective measures agreed upon by the international community.

But the consequences of the crisis are as far-reaching as to encompass the broader role of the Fund in the post-crisis international financial architecture. Two developments, part of the "Istanbul decision" (IMF, 2009k), stand out in this regard. First, the issue of whether macrofinancial stability should be explicitly included as an integral part of the Fund's institutional mandate (IMF, 2009i) has most prominently been recognized by the IMFC, at its October 2009 meeting, through its call on the Fund to "review its mandate to cover the full range of macroeconomic and financial sector policies that bear on global stability" (IMF, 2009j).

Furthermore, in launching the "Framework for Strong, Sustainable, and Balanced Growth" at their September 2009 Summit in Pittsburgh (Group of Twenty, 2009c), the G-20 Leaders 
called on the Fund to assist the G-20 countries in the new cooperative process of mutual assessment of their policies. This call, endorsed by the IMFC, is set to usher in a new kind of multilateral surveillance for the institution.

Ultimately, a candid, even-handed, and independent surveillance is "vital" to improve the role and effectiveness of the Fund in supporting stronger cooperation and ensuring a more sustainable global economy and international financial system (Group of Twenty, 2009b).

We believe that a strong, independent and accountable International Monetary Fund, by following up through its surveillance activities on the appropriate lessons drawn from the global financial crisis, can provide a crucial contribution to the international effort of restoring and preserving the "global public good" of macro-financial stability. 


\section{REFERENCES}

Basle Committee on Banking Supervision, 1997, "Core Principles for Effective Banking Supervision".

Bayoumi T. - Melander O., 2008, "Credit Matters: Empirical Evidence on U.S. Macro-Financial Linkages”. IMF Working Paper No. 08/169.

Boorman J., 2007, "An Agenda for the Reform of the International Monetary Fund". Emerging Markets Forum.

Bossone B., 2008, "Integrating Macroeconomic and Financial Sector Analyses within IMF Surveillance: A Case Study on IMF Governance”. Independent Evaluation Office Background Paper 08/11.

Boughton J. M., 2001, "Silent Revolution - The International Monetary Fund 19791989”. (Washington: International Monetary Fund).

Claessens S. - Kose M. A. - Terrones M., 2008, "What Happens During Recessions, Crunches, and Busts?”. IMF Working Paper No. 08/274. (Washington: International Monetary Fund).

Drees B. - Pazarbaşioğlu C., 1998, "The Nordic Banking Crises - Pitfall in Financial Liberalization?”. IMF Occasional Paper No. 161. (Washington: International Monetary Fund).

Enoch C. - Marston D. - Taylor M., 2002, "Building Strong Banks Through Surveillance and Resolution". (Washington: International Monetary Fund).

Evans O. - Leone A. M. - Gill M. - Hilbers P., 2000, "Macroprudential Indicators of Financial System Soundness”. IMF Occasional Paper No. 192. (Washington: International Monetary Fund).

Financial Stability Forum, 2000, “Issues Paper of the Task Force on Implementation of Standards".

Group of Seven, 1995, "Review of the International Financial Institutions”. G-7 Halifax Summit.

, 1996, "Economic Communiqué”. G-7 Lyon Summit.

, 1997, "Final Report to the G-7 Heads of State or Government on Promoting Financial Stability". G-8 Denver Summit.

, 1998a, "Strengthening the Architecture of the Global Financial System". Report of G-7 Finance Ministers to G-7 Heads of State or Government. G-7 Birmingham Summit. , 1998b, "Declaration of the G7 Finance Ministers and Central Bank Governors". Washington.

Washington. 2001, "Statement of G-7 Finance Ministers and Central Bank Governors". 
Group of Ten, 1997, "A Strategy for the Formulation, Adoption and Implementation of Sound Principles and Practices to Strengthen Financial Systems". Report of the Working Party on Financial Stability in Emerging Market Economies.

Group of Twenty, 2008, "Declaration of the Summit on Financial Markets and the World Economy”. Washington. System". London.

,2009a, 'Declaration of the Summit on Strengthening the Financial , 2009b, "Communiqué of the Meeting of Finance Ministers and Central Bank Governors". London. , 2009c, “Leaders' Statement: The Pittsburgh Summit".

Group of Twenty-two, 1998a, "Report of the Working Group on Transparency and Accountability". Washington.

Systems". Washington. 1998b, "Report of the Working Group on Strengthening Financial

Hilbers P. - Krueger R. - Moretti M., 1999, "Macroprudential Indicators - Seminar Discusses Ways to Assess Soundness of Financial System to Improve Surveillance". IMF Survey, Vol. 28, No. 18, September. (Washington: International Monetary Fund).

Independent Evaluation Office, 2006, "Financial Sector Assessment Program Evaluation Report". (Washington: International Monetary Fund).

International Monetary Fund, 1990, “The Determinants and Systemic Consequences of International Capital Flows". (Washington: International Monetary Fund).

, 1995a, "Biennial Review of the Implementation of the Fund's Surveillance over Members' Exchange Rate Policies, and of the 1977 Surveillance Decision. Summing Up by the Chairman". (Washington: International Monetary Fund).

, 1995b, "Mexico-Report on Fund Surveillance, 1993-94”. (Washington: International Monetary Fund).

, 1995c, "Mexico-Report on Fund Surveillance, 1993-94. Summing Up by the Chairman" (Washington: International Monetary Fund). , 1995d, "Report of the Executive Board to the Interim Committee on Strengthening of Fund Surveillance". (Washington: International Monetary Fund). , 1995e, "Review of Surveillance - Staff Operational Guidance Note". (Washington: International Monetary Fund).

, 1995f, "Communiqué of the Interim Committee of the Board of Governors of the International Monetary Fund". Press Release No. 95/27. (Washington: International Monetary Fund). 
, 1995g, "Communique of the Interim Committee of the Board of Governors of the International Monetary Fund". Press Release No. 95/51. (Washington: International Monetary Fund).

, 1996a, "Bank Soundness and Macroeconomic Policy". (Washington: International Monetary Fund).

, 1996b, "Communiqué of the Interim Committee of the Board of Governors of the International Monetary Fund". Press Release No. 96/48. (Washington: International Monetary Fund).

, 1997a, "Biennial Review of the Implementation of the Fund's Surveillance over Members' Exchange Rate Policies, and of the 1977 Surveillance Decision”. (Washington: International Monetary Fund).

, 1997b, "Biennial Review of the Implementation of the Fund's Surveillance over Members' Exchange Rate Policies, and of the 1977 Surveillance Decision. Summing Up by the Chairman". (Washington: International Monetary Fund).

, 1997c, "Toward a Framework for Sound Banking. Summing Up by the Chairman". (Washington: International Monetary Fund).

, 1997d, "Bank-Fund Collaboration in Strengthening Financial Sectors". (Washington: International Monetary Fund).

, 1998a, "Toward a Framework for Financial Stability". World Economic and Financial Surveys. (Washington: International Monetary Fund).

, 1998b, "Review of Members' Policies in the Context of SurveillanceLessons for Surveillance from the Asian Crisis". (Washington: International Monetary Fund).

,1998c, "Communiqué of the Interim Committee of the Board of Governors". Press Release No. 98/14. (Washington: International Monetary Fund). , 1998d, "International Standard and Fund Surveillance". (Washington: International Monetary Fund).

, 1998e, "Guidance Note for the Monitoring of Financial Systems under Article IV Surveillance”. (Washington: International Monetary Fund).

, 1998f, "Review of Bank-Fund Collaboration in Strengthening Financial Systems". (Washington: International Monetary Fund).

, 1999a, "International Standards and Fund Surveillance-Further Issues". (Washington: International Monetary Fund). , 1999b, “IMF-World Bank Financial Sector Assessment Program”. (Washington: International Monetary Fund). , 1999c, "External Evaluation of IMF Surveillance. Report by a Group of Independent Expert”. (Washington: International Monetary Fund). 
, 2000a, "Biennial Review of the Implementation of the Fund's

Surveillance over Members' Exchange Rate Policies, and of the 1977 Surveillance Decision". (Washington: International Monetary Fund).

,2000b, "Biennial Review of the Implementation of the Fund's

Surveillance over Members' Exchange Rate Policies, and of the 1977 Surveillance Decision. Summing Up by the Chairman". (Washington: International Monetary Fund).

,2000c, "Financial Sector Assessment Program-Progress Report-Lessons from the Pilot Exercise and Next Steps". (Washington: International Monetary Fund).

, 2000d, "Experience with Basel Core Principle Assessments". (Washington: International Monetary Fund).

,2000e, "Communiqué of the International Monetary and Financial Committee of the Board of Governors of the International Monetary Fund". Press Release No. 00/31. (Washington: International Monetary Fund).

Monetary Fund).

, 2000f, News Brief No. 00/93. October. (Washington: International

, 2000g, "Financial Sector Assessment Program-A Review-Lessons from the Pilot and Issues Going Forward". (Washington: International Monetary Fund).

, 2000h, "Financial Sector Assessment Program-A Review-Lessons from the Pilot and Issues Going Forward. Summing Up by the Acting Chairman". (Washington: International Monetary Fund).

,2000i, "Address by the Managing Director to the Board of Governors of the Fund". (Prague: International Monetary Fund).

, 2001, "Financial Soundness Indicators: Policy Paper". (Washington:

International Monetary Fund).

, 2002a, "Biennial Review of the Implementation of the Fund's Surveillance and of the 1977 Surveillance Decision - Overview". (Washington: International Monetary Fund).

, 2002b, "Biennial Review of the Implementation of the Fund's Surveillance and of the 1977 Surveillance Decision - Framework and Conduct of Surveillance in 2000-01”. (Washington: International Monetary Fund). , 2002c, "Biennial Review of the Implementation of the Fund's Surveillance over Members' Exchange Rate Policies, and of the 1977 Surveillance Decision. Summing Up by the Chairman". (Washington: International Monetary Fund).

, 2002d, "Operational Guidance Note for Staff Following the 2002 Biennial Surveillance Review”. (Washington: International Monetary Fund). 
,2003a, "Financial Sector Assessment Program - Review, Lessons, and Issues Going Forward". (Washington: International Monetary Fund). ,2003b, “The Acting Chair's Summing Up Financial Sector Assessment Program-Review, Lessons, and Issues Going Forward”. (Washington: International Monetary Fund).

Monetary Fund).

, 2003c, "Financial Soundness Indicators". (Washington: International ,2004, "Biennial Review of the Implementation of the Fund's Surveillance and of the 1977 Surveillance Decision - Content of Surveillance". (Washington: International Monetary Fund).

, 2005a, "Financial Sector Assessment Program - Review, Lessons, and Issues Going Forward”. (Washington: International Monetary Fund).

Monetary Fund). , 2005b, “Press Release No. 05/132”. (Washington: International ,2005c, "The Standards and Codes Initiative-Is It Effective?" (Washington: International Monetary Fund). ,2005d, "Financial Sector Assessment: A Handbook". (Washington: International Monetary Fund).

,2005e, "The Managing Director's Report on the Fund's Medium-Term Strategy." (Washington: International Monetary Fund). , 2006, “The Managing Director's Report on the Fund's Medium-Term Strategy". (Washington: International Monetary Fund). , 2007a, "Report of the Taskforce on Integrating Finance and Financial Sector Analysis into Article IV Surveillance". (Washington: International Monetary Fund).

,2007b, 'Bilateral Surveillance over Members' Policies - Executive Board Decision”. (Washington: International Monetary Fund).

, 2008a, "The Recent Financial Turmoil - Initial Assessment, Policy Lessons, and Implications for Fund Surveillance". (Washington: International Monetary Fund).

, 2008b, "The Managing Director's Statement on the Work Program of the Executive Board". (Washington: International Monetary Fund). ,2008c, “2008 Triennial Surveillance Review - Overview Paper”. (Washington: International Monetary Fund). , 2008d, “2008 Triennial Surveillance Review - Thematic Findings Paper". (Washington: International Monetary Fund). 
,2008e, "The Data Dissemination initiative After 10 Years". Edited by W. E. Alexander, J. Cady, and J. Gonzalez-Garcia. (Washington: International Monetary Fund).

, 2008f, "Communiqué of the International Monetary and Financial Committee of the Board of Governors of the International Monetary Fund". Press Release No. 08/240. (Washington: International Monetary Fund).

, 2009a, "Initial Lessons of the Crisis for the Global Architecture and the IMF”. (Washington: International Monetary Fund).

, 2009b, “Addressing Information Gaps". IMF Staff Position Note No. 06. (Washington: International Monetary Fund).

,2009c, "Economic and Financial Statistics in the Context of the Global Financial Crisis". (Washington: International Monetary Fund).

, 2009d, "Communiqué of the International Monetary and Financial Committee of the Board of Governors of the International Monetary Fund". Press Release No. 09/139. (Washington: International Monetary Fund).

, 2009e, "Financial Sector and Bilateral Surveillance-Toward Further Integration". (Washington: International Monetary Fund). , 2009f, "Financial Sector Assessment Program After Ten YearsExperience and Reforms for the Next Decade". (Washington: International Monetary Fund).

, 2009g, "Financial Sector Assessment Program After Ten YearsBackground Material-Experience and Reforms for the Next Decade". (Washington: International Monetary Fund).

,2009h, "Revised Approach to Financial Regulation and Supervision

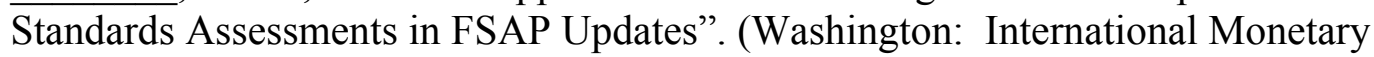
Fund).

, 2009i, "Statement by the Managing Director to the IMFC on the IMF's

Post-Crisis Role". (Washington: International Monetary Fund).

, 2009j, "Communiqué of the International Monetary and Financial Committee of the Board of Governors of the International Monetary Fund". Press Release No. 09/347. (Istanbul: International Monetary Fund).

, 2009k, "Opening Address by the Managing Director to the 2009 Annual Meetings of the Boards of Governors of the World Bank Group and the International Monetary Fund". (Istanbul: International Monetary Fund).

, 20091, “IMF-FSB Early Warning Exercise Factsheet”. Available at: http://www.imf.org/external/np/exr/facts/ewe.htm. (Washington: International Monetary Fund).

Johnson R. B. - Sundararajan V., 1999, "Sequencing Financial Sector Reforms”. (Washington: International Monetary Fund). 
Jones M. - Hilbers P. - Slack G., 2004, "Stress Testing Financial Systems: What to Do When the Governor Calls". IMF Working Paper No. 04/127. (Washington: International Monetary Fund).

Kenen P. B., 2001, “The International Financial Architecture: What's New? What's Missing?” Peterson Institute for International Economics. Washington.

Lavigne R. - Schembri L., 2009, "Strengthening IMF Surveillance: An Assessment of Recent Reforms". Bank of Canada Discussion Paper 2009-10. (Ottawa: bank of Canada).

Lindgren C. J. - Garcia G. - Saal M. I., 1996, "Bank Soundness and Macroeconomic Policy". (Washington: International Monetary Fund).

Porter T., 2000, "The G-7, the Financial Stability Forum, the G-20, and the Politics of International Financial Regulation”. Paper presented at the International Studies Association annual meeting, Los Angeles, 15 March.

Saccomanni F., 2000, “A New Architecture or a New System? A Survey of International Monetary Reform in the 1990s". Open Economies Review, No. 11, Supplement 1, pp. 15-41. ,2008, "Managing International Financial Instability. National Tamers Versus Global Tigers". Edward Elgar, Cheltenham, U.K.

Schinasi G. J., 2006, "Safeguarding financial Stability - Theory and Practice”. (Washington: International Monetary Fund).

Sobel M. - Stedman S., 2006b, "The Evolution of the G-7 and Economic Policy Coordination". Occasional Paper No. 3, Department of the Treasury - Office of International Affairs.

Sundararajan V. - Baliño T. J. T., 1991, "Banking Crises: Cases and Issues". (Washington: International Monetary Fund).

Truman E. M. (editor), 2006, "Reforming the IMF for the 21st Century". Peterson Institute for International Economics, Special Report 19. Washington. ,2009, "The IMF and the Global Crisis: Role and Reform". Peterson Institute for International Economics. Washington. 